\title{
Ectopic histone clipping in the mouse model of progressive myoclonus epilepsy
}

\author{
Eduard Daura ${ }^{a, b}$, Saara Tegelberga,b, Masahito Yoshiharac ${ }^{\mathrm{c}}$, Christopher Jackson ${ }^{\mathrm{d}}$, Francesca \\ Simonettia,b, Katri Aksentjeff ${ }^{a, b}$, Sini Ezera,b, Paula Hakala,b, Shintaro Katayama a,b,c, Juha \\ Kere $^{a, c, d}$, Anna-Elina Lehesjokia,b, ${ }^{,}$, Tarja Joensuu, ${ }^{a, b}$ \\ a Folkhälsan Research Center, 00290, Helsinki, Finland \\ b M edicum, Faculty of M edicine, University of Helsinki, 00290, Helsinki, Finland \\ c Department of Biosciences and Nutrition, Karolinska Institutet, 141 83, Stockholm, \\ Sweden \\ d Stem Cells and Metabolism Research Program, Faculty of Medicine, University of \\ Helsinki, 00290, Helsinki, Finland \\ * Correspondence should be addressed to anna-elina.lehesjoki@helsinki.fi
}

\begin{abstract}
We establish cystatin $\mathrm{B}$ (CSTB) as a regulator of histone $\mathrm{H} 3$ tail clipping in murine neural progenitor cells (NPCs) and provide evidence suggesting that epigenetic dysregulation contributes to the early pathogenesis in brain disorders associated with deficient CSTB function. We show that NPCs undergo regulated cleavage of the N-terminal tail of histone $\mathrm{H} 3$ at threonine 22 (H3T22) transiently upon induction of differentiation. CSTB-deficient NPCs present premature activation of H3T22 clipping during self-renewal mediated by increased activity of cathepsins $L$ and $B$. During differentiation, the proportion of immature committed neurons undergoing H3T22 clipping is significantly higher in CSTBdeficient than in wild-type NPCs, with no observable decline within 12 days postdifferentiation. CSTB-deficient NPCS exhibit significant transcriptional changes highlighting altered expression of nuclear-encoded mitochondrial genes. These changes are associated with significantly impaired respiratory capacity of differentiating NPCS devoid of CSTB. Our data expand the mechanistic understanding of diseases associated with CSTB deficiency.
\end{abstract}




\section{INTRODUCTION}

Progressive myoclonus epilepsy, EPM 1 (Unverricht-Lundborg disease; OM IM 254800) is caused by biallelic loss-of-function mutations in cystatin B (CSTB) (Pennacchio et al., 1996; Lalioti et al., 1997), encoding a cysteine protease (cysteine cathepsin) inhibitor with a largely unknown physiological function (Rawlings and Barrett, 1990; Turk and Bode, 1991). EPM 1 is a neurodegenerative disease characterized by onset between 6 and 16 years of age, progressive drug-resistant myoclonus, epilepsy, and ataxia (Kälviäinen et al., 2008) (Fig. 1). Brain magnetic resonance imaging of EPM 1 patients have revealed cortical and thalamic atrophy, as well as widespread white matter degeneration (Koskenkorva et al., 2009; Koskenkorva et al., 2012; M anninen et al., 2013). The majority of EPM 1 patients are homozygous for a dodecamer repeat expansion mutation in the promoter region of CSTB, resulting in significantly reduced CSTB protein expression and, consequently, increased activity of cathepsins B, L and S (Rinne et al., 2002; Joensuu et al., 2007). Total loss of CSTB causes neonatal-onset encephalopathy with progressive microcephaly and hypomyelination (M ancini et al., 2016; O'Brien et al., 2017) implying an important role for CSTB in brain development (Fig. 1).

A Cstb-knockout (Cstb ${ }^{-/}$) mouse model recapitulates key features of EPM 1 including myoclonus, ataxia and progressive brain degeneration (Pennacchio et al., 1998; Shannon et al., 2002; Buzzi et al., 2012; Tegelberg et al., 2012; M anninen et al., 2013; M anninen et al., 2014) (Fig. 1). We previously demonstrated that early microglial activation and dysfunction with consequent inflammation in the $\mathrm{Cstb}^{-1-}$ mouse brain precedes the onset of myoclonus and neurodegeneration (Tegelberg et al., 2012; Okuneva et al., 2015; Okuneva et al., 2016). We further showed that in the developing cerebellum, preceding microglial activation, Purkinje cells present imbalance between excitatory and inhibitory postsynaptic currents, impairment of ligand binding to $G_{A B A}$ receptors and increased expression of GABA receptor subunit $\alpha 6$ and $\delta$ genes (Joensuu et al., 2014). These early alterations in GABAergic signaling, observed at post-natal day seven, suggest that CSTBdeficiency interferes with the development and/or maturation of neuronal networks.

Within the cell, CSTB localizes to the nucleus and the cytosol, where it is associated with a subset of lyso somes (Riccio et al., 2001; Brännvall et al., 2003; Alakurtti et al., 2005). In the nucleus, CSTB interacts with cathepsin L (Ceru et al., 2010; Chauhan et al., 2016), a protease with several reported nuclear functions including regulation of cell cycle progression through proteolytic processing of CDP/Cux transcription factor, stabilization of epigenetic heterochromatin markers, sperm histone degradation, and histone $\mathrm{H} 3$ tail clipping (Goulet et al., 2004; Bulynko et al., 2006; Duncan et al., 2008; Adams-Cioaba et al., 2011; Morin et al., 2012). Cathepsin $L$ is one of several intracellular proteases that have emerged as epigenetic regulators through their ability to remove histone tails, particularly during cell-state transitions (e.g. Duncan et al., 2008; Khalkhali-Ellis et al., 2014; Kim et al., 2016; Yi and Kim, 2018). Histone tail clipping implies a quick and irreversible erasure of epigenetic signatures from the nucleosome, and impacts nuclear 
processes from gene expression to higher-order chromatin structure (Santos-Rosa et al., 2009; Nurse et al., 2013). The upstream regulation and downstream effects of this mechanism are poorly defined, which makes it one of the least understood modalities of histone post-translational modification (reviewed by Yi and Kim (2018)).

Given the function of CSTB as an endogenous inhibitor of cathepsin L, its localization in the nucleus and its predicted role in brain development, implied by both human and mouse data, we explored the hypothesis that CSTB is involved in chromatin remodeling during brain development. We found that CSTB functions as an endogenous modulator of histone $\mathrm{H} 3$ tail clipping through the inhibition of cysteine cathepsins $\mathrm{B}$ and $\mathrm{L}$, and that absence of CSTB results in ectopic H3 clipping.

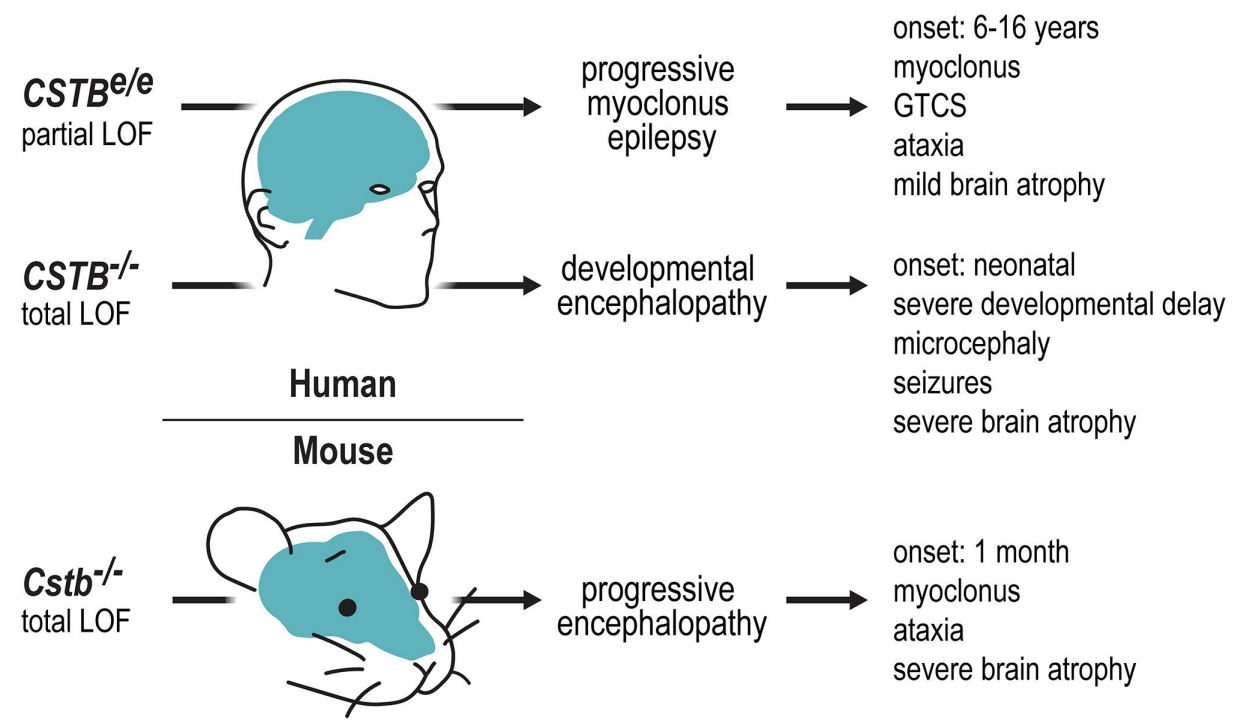

Figure 1: Phenotypes associated with biallelic loss of CSTB function. In human, partial loss of function (LOF) due to homozygosity for a repeat expansion in the promoter of CSTB gene (CSTB ${ }^{\mathrm{e}} \mathrm{e}$ ) underlies progressive myoclonus epilepsy with onset in late childhood/adolescence. Total loss of function due to biallelic null mutations (CSTB ${ }^{-1-}$ ) leads to a neonatal-onset developmental encephalopathy. Cstb knock-out mice (Cstb ${ }^{-1}$ ) show a neurodegenerative disorder with neuronal hyperexcitability and glial activation preceding the onset of clinical symptoms by 1 month of age. GTCS: generalized tonic-clonic seizures. 


\section{RESULTS}

\section{CSTB regulates histone H3 tail clipping during neural stem cell renewal and differentiation}

Proteolytic removal of the $\mathrm{N}$-terminal tail of histone $\mathrm{H} 3$ (histone clipping) has been observed in a number of cell types and physiologic conditions (e.g. Duncan et al., 2008; Santos-Rosa et al., 2009; Duarte et al., 2014; Khalkhali-Ellis et al., 2014; Kim et al., 2016; Melo et al., 2017; Shen et al., 2017). However, it is not known whether this mechanism is involved in neural stem cell differentiation. To address this question, we generated an in vitro model of neural stem cell renewal and differentiation from embryonic mouse brain (Fig. 2A). We acid-extracted histones from wild-type (wt) mouse neural progenitor cells (NPCS) during self-renewal (undifferentiated; $u D$ ) and differentiation (days 1, 5 and 12 post-differentiation; $p D$ ), and analyzed them by Western blotting using different antibodies against histone $\mathrm{H3}$. In addition to the expected $\mathrm{H} 3$ band of approximately 16 $\mathrm{kDa}$, we detected two faster-migrating $\mathrm{H} 3$ species, both of which appeared specifically upon induction of differentiation (Fig. 2B-C). An antibody against $\mathrm{H} 3 \mathrm{~K} 4 \mathrm{me} 3$ only detected the intact form of histone $\mathrm{H} 3$, implying that the faster-migrating $\mathrm{H} 3$ species are the result of $\mathrm{N}$-terminal truncation. The lighter of the cleaved $\mathrm{H} 3$ species was identified both with an antibody against the C-terminus of histone $\mathrm{H} 3$ (Fig. 2B-C) and with one against H3K27me3 (Fig. 2B; Supplementary Appendix, Fig. 2-1). These observations indicate that this cleaved $\mathrm{H} 3$ product has undergone $\mathrm{N}$-terminal proteolysis proximal to the lysine at position 27. The heavier cleavage product was found to correspond to histone H3 truncated between alanine 21 and threonine 22 (hereinafter referred to as H3T22Cl), based on specific staining with a monoclonal antibody that recognizes $\mathrm{H} 3$ with threonine 22 at its N-terminal end (Fig. 2B-C; Supplementary Appendix, Fig. 2-1).

We next investigated the potential involvement of CSTB in the regulation of histone clipping and carried out Western blot analysis of histone extracts derived from Cstbmouse NPCs during self-renewal and differentiation. We confirmed the presence of the two histone $\mathrm{H} 3$ cleavage products in differentiating cells (Fig. 2B). Notably, we detected the H3T22Cl band also in undifferentiated NPCs (Fig. 2B), suggesting that CSTB-deficient cells undergo ectopic H3T22 clipping during self-renewal.

In order to find out whether histone $\mathrm{H} 3$ tail clipping also occurs in vivo and is not a phenomenon induced by cell culture conditions, we analyzed its presence in histone extracts from brains of wt and Cstb ${ }^{-/}$embryonic day (E) 13.5 mouse embryos by Western blotting. We detected H3T22 $\mathrm{Cl}$ in both wt and $\mathrm{Cstb}^{-1-}$ brain samples (Fig. 2D) with the abundance of H3T22 $\mathrm{cl}$ being approximately five-fold higher in Cstb $\mathrm{H}^{-1}$ samples $\left(\mathrm{t}_{(8)}=2.968\right.$, $p=0.017$, t-test). $\mathrm{H} 3 \mathrm{~T} 22 \mathrm{cl}$ in both genotypes was still readily observable in primary neurospheres after six days in culture but markedly decreased in abundance following passage to secondary neurospheres (Fig. 2D). Cstb ${ }^{\%}$ cells showed significantly higher 
levels of $\mathrm{H} 3 \mathrm{~T} 22 \mathrm{Cl}$ at both cellular stages (primary neurospheres: $\mathrm{t}_{(4)}=3.865, \mathrm{p}=0.018$, $\mathrm{t}$ test; secondary neurospheres: $t_{(6)}=3.510, p=0.013$, t-test; Fig. 2D), reflecting dysregulated histone clipping in the absence of CSTB taking place both in vivo and at successive stages of in vitro NPC amplification. We did not observe the lighter $\mathrm{H} 3$ cleavage product in embryonic tissue samples (Fig. 2D). Moreover, this cleavage product was absent in undifferentiated Cstb ${ }^{-1-}$ NPCs (Fig. 2B), implying that its regulation, contrary to that of $\mathrm{H} 3 \mathrm{~T} 22 \mathrm{Cl}$, is independent from CSTB.

We focused our further analyses on characterizing the occurrence of H3T22cl on cellular level. We stained wt and Cstb-1- NPCs for H3T22cl and nuclear DNA following induction of differentiation. We observed that the truncated product of histone $\mathrm{H} 3$ localized exclusively within the cell nucleus (Fig. 2E). We found that only a small fraction of wt cells was immunopositive for $\mathrm{H} 3 \mathrm{~T} 22 \mathrm{cl}$, with the number of $\mathrm{H} 3 \mathrm{~T} 22 \mathrm{Cl}^{+}$cells decreasing along differentiation $\left(2.8 \%, 1.2 \%\right.$, and $0.7 \%$ at days 2,5 , and $12 \mathrm{pD}$, respectively; $F_{(2,40)}=52.64$, $p=0.0117$, ANOVA; Fig. 2E). These data imply that H3T22 clipping in wt cells occurs transiently upon cellular induction. In line with these findings and the suggested role of CSTB in regulation of H3T22 clipping, RT-qPCR of Cstb expression showed that both selfrenewing and differentiating wt NPCs express Cstb and that the mRNA level of Cstb significantly increases through differentiation $\left(F_{(4,16)}=182.9, p<0.0001\right.$, ANOVA; Fig. 2F). Concordantly, in differentiating $\mathrm{Cstb}^{-1-} \mathrm{NPCS}$, the number of $\mathrm{H}^{2} 22 \mathrm{Cl}^{+}$cells was significantly higher (5-fold or greater) than in wt cells $\left(F_{(5,78)}=15.31, p<0.0001\right.$ at day 2 $p D, p=0.0003$ at day 5 pD, $p<0.0001$ at day 12 pD, ANOVA) and presented no observable decrease over time (Fig. 2E).

Finally, we sought to carry out rescue of ectopic histone clipping in CSTB-deficient NPCS by overexpressing Cstb transiently in $\mathrm{Cstb}^{-1}$ NPCs with green fluorescent protein (GFP) as a transfection control. Twenty-four hours post-transfection, we triggered NPC differentiation followed by immunofluorescence staining for $\mathrm{H} 3 \mathrm{~T} 22 \mathrm{Cl}$ at day $1 \mathrm{pD}$. Quantification of the proportion of cells double positive for GFP and H3T22cl revealed that overexpression of CSTB is sufficient to almost completely block differentiationassociated histone clipping $\left(\mathrm{t}_{(4)}=4.683, \mathrm{p}=0.009\right.$, $\mathrm{t}$-test; Fig. $\left.2 \mathrm{G}\right)$. Taken together, our data suggest that NPCs undergo regulated cleavage of histone $\mathrm{H} 3$ at position T22 during differentiation, and suggest that CSTB is in hibiting this chromatin remodeling event during self-renewal of NPCs and limiting its extent and timing during their differentiation. 
$2 \mathrm{~A}$

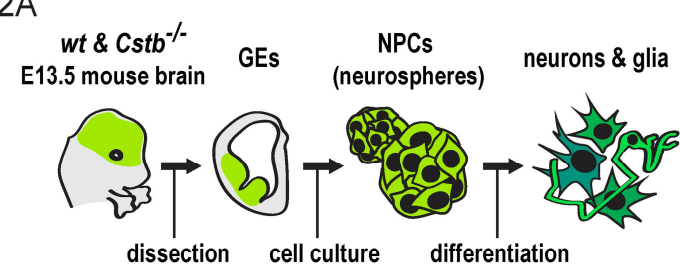

2B

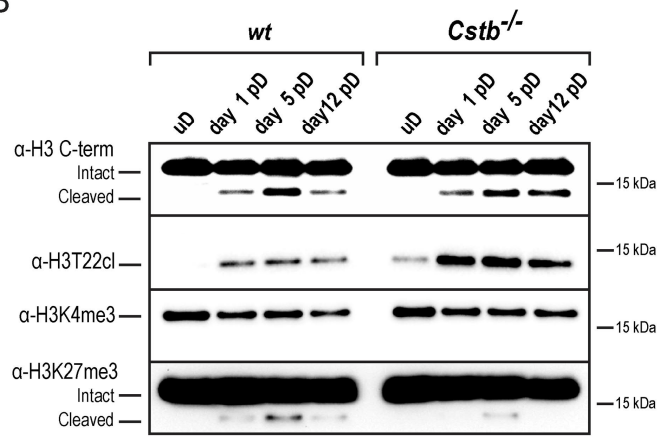

$2 \mathrm{C}$

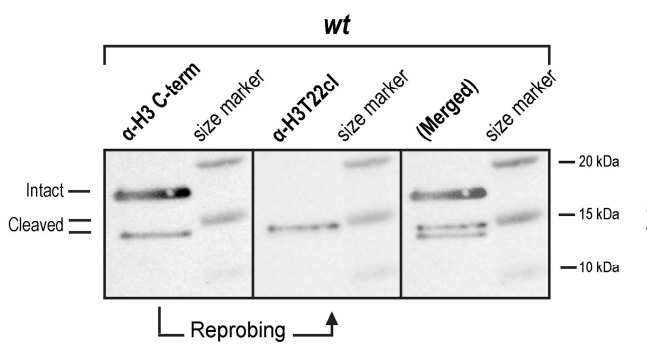

$2 \mathrm{D}$

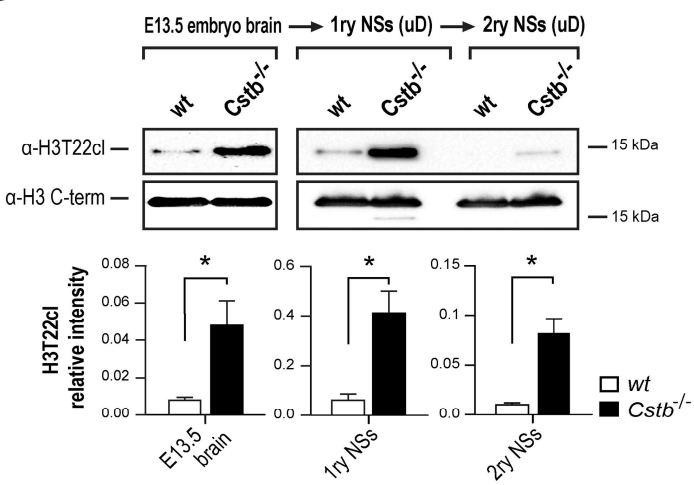

$2 \mathrm{E}$
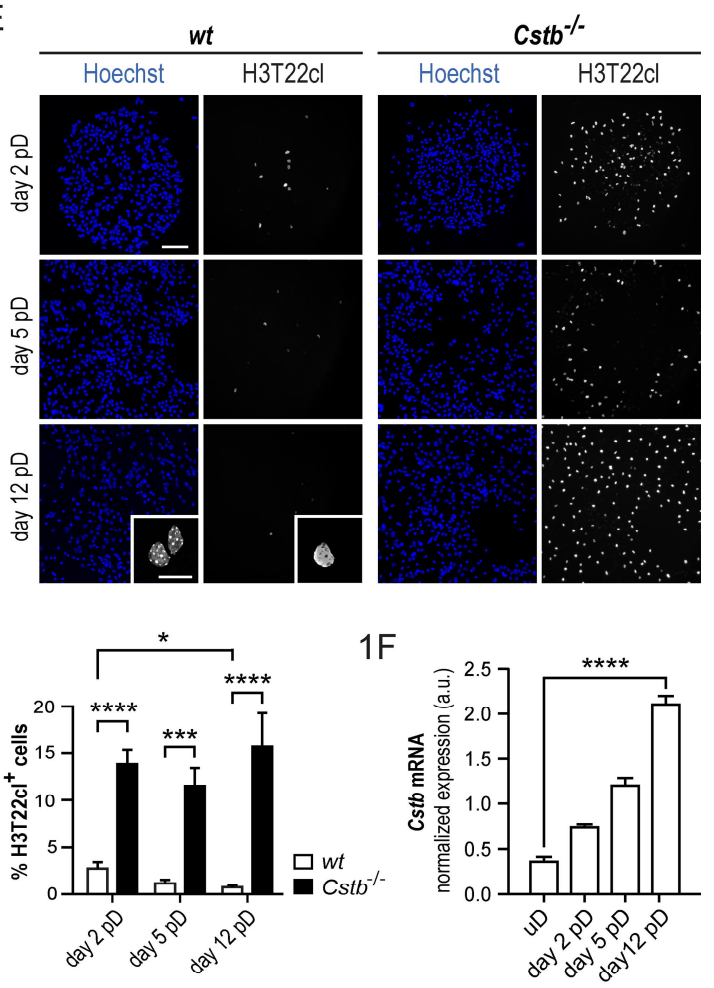

$2 \mathrm{G}$

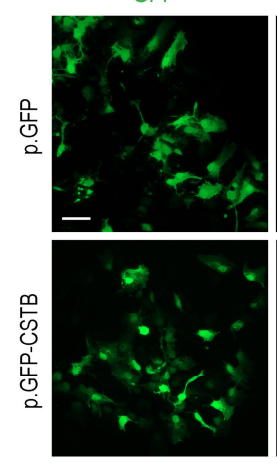

H3T22CI

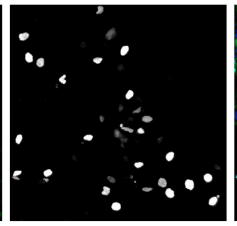

Merged / Hoechst
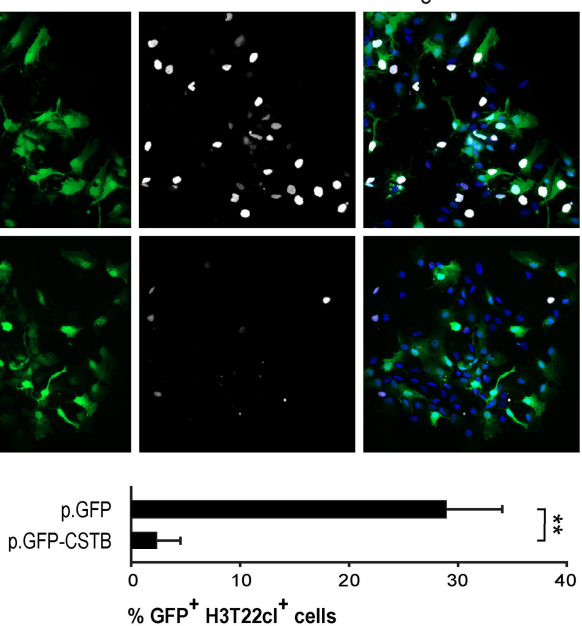

Figure 2: CSTB prevents ectopic clipping of the histone H3 tail in NPCs. A: Schematic representation of the experimental model used in this study. Briefly, NPCs derived from the ganglionic eminences (GEs) of wt and Cstb ${ }^{-/}$E13.5 mouse embryos were selectively amplified in vitro as neurospheres, plated for differentiation and allowed to differentiate for up to 12 days. B: Western blot analysis of different histone $\mathrm{H} 3$ modifications in histone extracts collected from wt and Cstb ${ }^{-1}$ NPCs before induction of differentiation (undifferentiated, uD) and at days 1, 5 and 12 after induction of differentiation (post-differentiation, pD) using antibodies against the C-terminus of H3, H3T22 Cl, H3K4me3 and H3K27me3. C: Sequential Western blot detection of truncated products of histone H3 in wt NPCs at day $5 \mathrm{pD}$ using antibodies against the C-terminus of $\mathrm{H} 3$ and $\mathrm{H} 3 \mathrm{~T} 22 \mathrm{Cl}$. D: Western blot analysis of the relative abundance of H3T22Cl in histone extracts of wt and Cstb ${ }^{-1}$ E13.5 mouse embryo forebrains and cultured undifferentiated (uD) primary and secondary neu rospheres (1ry and 2ry NSs). H3T22cl intensity value was normalized to that of total H3 detected with an antibody against the $\mathrm{C}$-terminus of $\mathrm{H3}(\mathrm{n}=3-5)$. E: Representative immunofluorescence images of differentiating wt and $\mathrm{Cstb}^{-/} \mathrm{NPCs}$ stained for H3T22cl and DNA using Hoechst stain. Scale bar $=100 \mu \mathrm{m}$. Confocal microscopy images showing a H3T22cl-positive and a H3T22cl-negative cell are displayed in the insets of wt day $12 \mathrm{pD}$ figures. Scale bar $=20 \mu \mathrm{m}$. The chart depicts the proportion of H3T22cl-positive cells over total cell count. ( $n=13-15)$. F: RT-qPCR analysis of Cstb mRNA in self-renewing and differentiating wt NPCs. The chart depicts Cstb expression normalized to mRNA level of Rpl19 $(n=5)$. The results were posteriorly validated by normalization to mRNA levels of Atp5c1 and Ywhaz ( $n=5$; data not shown). G: Representative immunofluorescence images of differentiating Cstb $\%$ NPCs overexpressing GFP (p.GFP) or GFP-CSTB (p.GFP-CSTB). Cells were stained for H3T22cl and DNA using Hoechst stain. Scale bar $=20 \mu \mathrm{m}$. The chart depicts H3T22cl / GFP positive cells over GFP positive cells $(\mathrm{n}=3) . * p<0.05, * * p<$ $0.01, * * * p<0.001, * * * * p<0.0001$. 


\section{Cathepsins B and L mediate ectopic histone H3 tail clipping in CSTB-deficient neural progenitor cells}

CSTB is an endogenous inhibitor of cathepsin L, a previously established H3T22 protease in mouse embryonic stem cells (Duncan et al., 2008). To determine whether cathepsin L is responsible for H3T22 clipping also in the neural cell lineage, we first cultured undifferentiated $\mathrm{Cstb}^{-1-}$ NPCs in the presence of the highly selective cysteine protease inhibitor E-64 or the cathepsin B and L inhibitor Z-FF-FMK. We then evaluated the capability of these compounds to prevent ectopic histone $\mathrm{H} 3$ clipping using Western blot analysis of acid-extracted histones. In $\mathrm{Cstb}^{-1-}$ cells cultured with either compound, the H3T22cl band was completely abolished $\left(E-64: F_{(2,15)}=174.6, p<0.0001\right.$, ANOVA; Z-FFFM K: $F_{(2,6)}=21.3, p=0.003$, ANOVA; Fig. $\left.3 A\right)$, suggesting that CSTB modulates $\mathrm{H} 3$ tail clipping through the inhibition of cathepsin $L$ and/or cathepsin $B$. We next measured the enzymatic activity of cathepsins $L$ and $B$ in whole cell lysates of wt and Cstb- NPCs. We detected an increase in the activity of both cathepsins in Cstb ${ }^{-1-}$ cells, implying decreased inhibition of activity in the absence of CSTB (Fig. 3B). The activity of cathepsin L was approximately 0.2 -fold higher in $\mathrm{Cstb}^{-1}$ - than in wt control NPCs $\left(\mathrm{t}_{(9)}=3.48, \mathrm{p}=0.007\right.$, $\mathrm{t}$ test), whereas we observed an approximately 7-fold higher cathepsin B activity in Cstb-1compared to wt cells $\left(t_{(8)}=31.95, p<0.0001\right.$, t-test). Finally, we cultured Cstb ${ }^{-1-N P C s}$ in the presence of the cathepsin B inhibitor CA-074. This compound strongly suppressed cathepsin B activity in the NPCs $\left(\mathrm{t}_{(6)}=13.02, \mathrm{p}<0.0001\right.$, t-test; Fig. 3C). However, it caused only a partial decrease in the abundance of $\mathrm{H} 3 \mathrm{~T} 22 \mathrm{Cl}\left(\mathrm{F}_{(2,6)}=18.66, p=0.018\right.$, ANOVA; Fig. $3 A)$. Taken together, these data suggest that both cathepsins $B$ and $L$ are responsible for ectopic histone $\mathrm{H} 3$ tail clipping in CSTB-deficient NPCS.
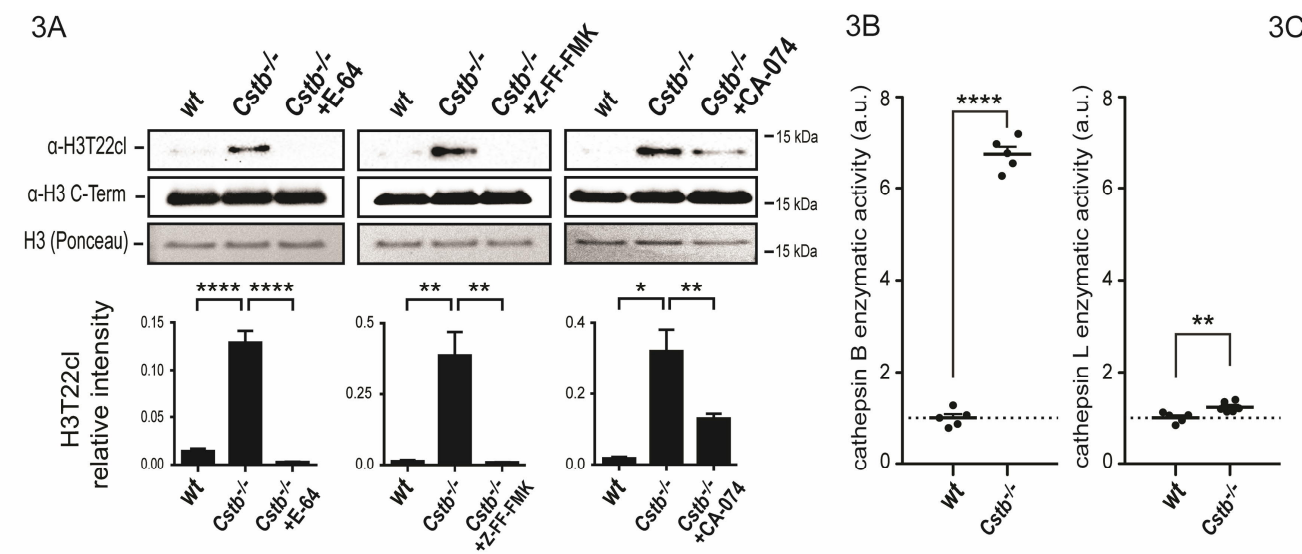

$3 C$

Figure 3: Cathepsins B and $L$ are responsible for ectopic histone H3 clipping in Cstb/. NPCs. A: Western blot analysis and quantification of H3T22Cl abundance in undifferentiated Cstb ${ }^{-/}$NPCs treated with E64 $(n=4-8)$, Z-FF-FMK $(n=3)$ and CA-074 $(n=$ 3). The capacity of each compound to block H3T22 clipping was evaluated through comparison with corresponding vehicle-treated wt and $\mathrm{Cstb}^{-1} \mathrm{NPCs}$. H3T22cl intensity value was normalized to that of total $\mathrm{H3}$, detected with an antibody against $\mathrm{H} 3 \mathrm{C}$-terminus. Total H3 detected with Ponceau staining is also shown. B: Scatter plots depicting enzymatic activity of cathepsins B and Lin whole cell lysates of undifferentiated Cstb ${ }^{-1}$ NPCs relative to wt NPCs levels (dotted lines) $(n=5-6)$. C: Scatter plot depicting enzymatic activity of cathepsin B in whole cell lysates of undifferentiated Cstb ${ }^{-/}$NPCs treated with CA-074 relative to vehicle-treated Cstb ${ }^{-1-}$ control NPCs (dotted line) $(n=4) . * p<0.05, * * p<0.01, * * * * p<0.0001$. 


\section{H3T22 clipping is most frequent in doublecortin-positive neurons}

We observed that only a small fraction of differentiating wt NPCs are immunopositive for H3T22Cl (Fig. 2D). To find out whether histone clipping is associated with cell proliferation, we first stained cells for Ki-67, the expression of which is confined to actively proliferating cells (Gerdes et al., 1983). We observed that a small proportion of H3T22cl positive cells expressed Ki-67 at day 12 pD in wt and at all three assessed timepoints in Cstb-1- cells (Supplementary Appendix, Fig. 4-1), indicating that histone clipping occurs both in dividing and in non-dividing cells with a strong preference for the latter.

To elucidate whether histone clipping occurs in all cell types or is limited to a specific cell type of the neural lineage, we next carried out immunofluorescence staining of differentiating wt NPCs for a number of cellular identity markers and quantified their coexpression with $\mathrm{H} 3 \mathrm{~T} 22 \mathrm{Cl}$. In order to address whether CSTB deficiency causes alterations in cell type specificity of histone clipping we did the experiments parallelly in Cstb ${ }^{-1-N P C s . ~}$

We first analyzed H3T22 cl in differentiating neurons. Approximately $3 \%$ of both wt and Cstb $^{-1}$ cells at day $12 \mathrm{pD}$ were positive for the neuron-specific tubulin isoform TUBB3 (TUJ $1 ; 2.84 \pm 0.44 \%$ of wt, $3.14 \pm 0.56 \%$ of Cstb $^{-1} ; n=6$ ). Its expression was more prevalent in cells undergoing $\mathrm{H} 3$ tail clipping, with $10 \%-20 \%$ of $\mathrm{H}_{3} \mathrm{~T} 22 \mathrm{Cl}^{+}$cells being $\mathrm{TUJ} 1^{+}$neurons (Supplementary Appendix, Fig. 4-2) in both genotypes at all three timepoints assessed. Staining with an antibody against doublecortin (DCX) showed that approximately $9 \%$ of wt cells at day $2 \mathrm{pD}$, and approximately $12 \%$ at day $12 \mathrm{pD}$ were committed, immature neurons with similar proportions seen in Cstb-/ cells (Supplementary Appendix, Fig. 4-3). The vast majority of $\mathrm{H}_{3} \mathrm{~T} 22 \mathrm{Cl}^{+}$cells were $\mathrm{DCX}^{+}$neurons. At day $2 \mathrm{pD}, \mathrm{DCX}$ was expressed in approximately $80 \%$ of $\mathrm{H}_{3 \mathrm{~T}} 22 \mathrm{Cl}{ }^{+}$cells and at day $12 \mathrm{pD}$ in approximately $90 \%$ of $\mathrm{H}_{3} \mathrm{~T}_{22} \mathrm{Cl}^{+}$ cells in both genotypes (Fig. 4A).

Next, we analyzed $\mathrm{H} 3 \mathrm{~T} 22 \mathrm{cl}$ in differentiating glia. During astrocyte maturation, nestin becomes progressively downregulated as cells accumulate glial fibrillary acidic protein (GFAP) (Sergent-Tanguy et al., 2006). We found that differentiating Cstb ${ }^{-/}$NPCs undergo transition from nestin ${ }^{+}$GFAP- to nestin ${ }^{-} \mathrm{GFAP}^{+}$expression at a faster rate than wt cells (nestin +GFAP: Chisq $=9.261, p=0.002$, linear mixed model; nestin ${ }^{-G F A P+}$ : Chisq $=16.688$, $p=4.405 \mathrm{E}-05$, linear mixed model), implying an impairment in the timeline of astrogliogenesis (Fig. 4B). We found that, in both genotypes, only a minority of $\mathrm{H}_{3} \mathrm{~T} 22 \mathrm{Cl}^{+}$ cells were immunopositive for either nestin or GFAP, whereas the majority of $\mathrm{H}_{3} 22 \mathrm{Cl}^{+}$ cells ( $83 \%$ and $86 \%$ at days 2 and 12 pD, respectively) were negative for both markers (Supplementary Appendix, Fig. 4-4). Using immunostaining against the oligodendrocyte antigen 04, we detected late oligodendrocyte precursors in low frequency (less than 1\% at days 2 and $12 \mathrm{pD}$ in both genotypes). We quantified that $2 \%-7 \%$ of all $04^{+}$cells were immunopositive for $\mathrm{H} 3 \mathrm{~T} 22 \mathrm{Cl}$, the proportion of $\mathrm{H}_{3} \mathrm{~T}_{22} \mathrm{Cl}^{+} \mathrm{O}^{+}$cells being significantly higher in CSTB-deficient conditions (40\%-49\%; $F_{(3,19)}=8.471, p=0.007$ at day $2 p D, p=$ 0.004 at day 12 pD, ANOVA; Supplementary Appendix, Fig. 4-5). 
Taken together these data imply that all three major cell types of neural origin undergo H3T22 cleavage during differentiation and suggest that this epigenetic mechanism is most prevalent among cells committed to a neuronal fate. To gain further support to this observation, we induced differentiation of wt NPCs in media with altered compositions to either promote or depress neuronal differentiation. Setup efficacy was validated through quantification of GFAP ${ }^{+}$and TUJ $1^{+}$cells at day $12 \mathrm{pD}$ (Supplementary Appendix, Fig. 4-6). Staining for H3T22cl revealed that, compared to cells cultured in the astrocyte media, NPCs cultured in neuronal differentiation promoting media displayed a significantly higher number of $\mathrm{H} 3 \mathrm{~T} 22 \mathrm{Cl}^{+}$cells, consistent with enhanced production of neurons $\left(F_{(5,18)}=7.447, p>0.016\right.$ at day $2 p D, p=0.003$ at day $5 p D, p=0.228$ at day 12 pD, ANOVA, Fig. 4C).

$4 \mathrm{~A}$

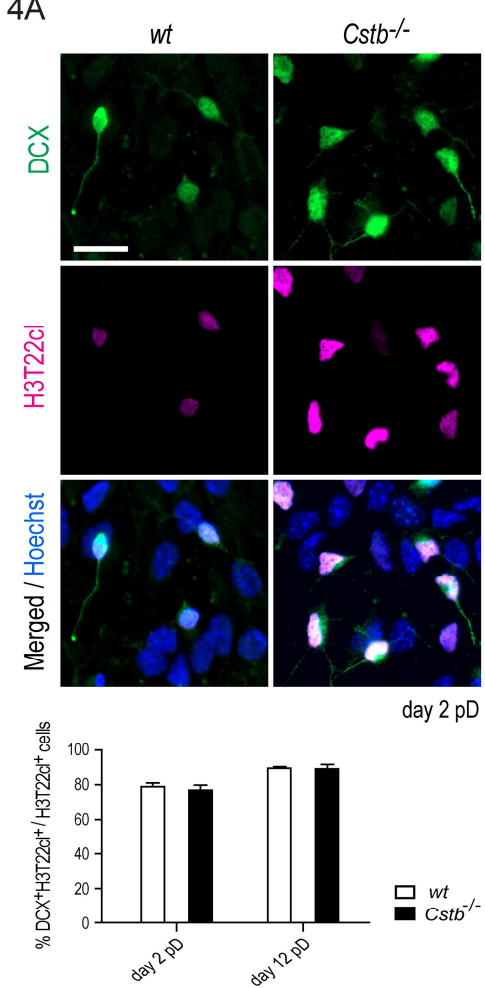

4B
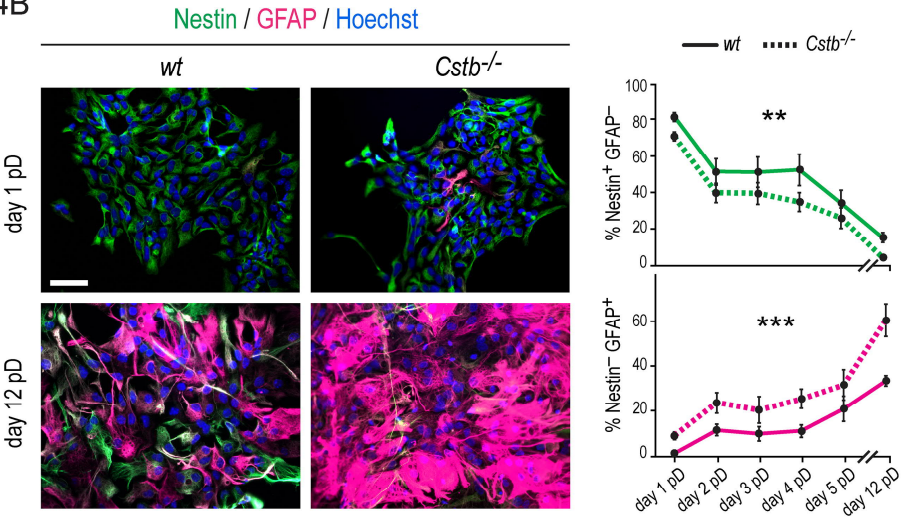

$4 \mathrm{C}$

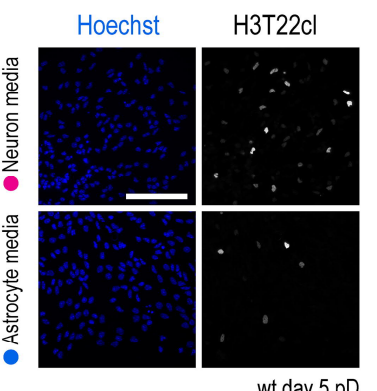

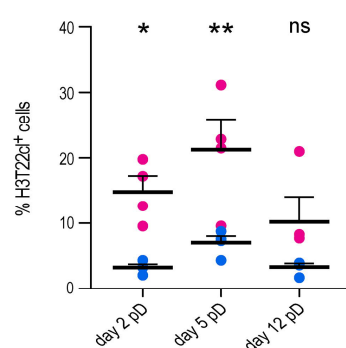

Figure 4: Astrogliogenesis is enhanced in differentiating Cstb/- NPCs yet H3T22 clipping is more prevalent in committed neurons. A: Representative immunofluorescence images of differentiating wt and Cstb-1-NPCs stained for doublecortin (DCX), H3T22cl and DNA using Hoechst stain. Scale bar $=20 \mu \mathrm{m}$. Bar plot depicts the proportion of DCX-positive cells among H3T22cl-positive cells $(n=$ 6). B: Representative immunofluorescence image of differentiating wt and Cstb ${ }^{-1}$ NPCs stained for nestin, GFAP and DNA. Scale bar $=50 \mu \mathrm{m}$. The charts depict the proportion of GFAP-negative nestin-positive cells and GFAP-positive nestin-negative cells over total cell count at six timepoints $\mathrm{pD}(\mathrm{n}=8)$. C: wt NPCs differentiated in neurogenesis-promoting media (Neuron media) or astrogliogenesis-promoting media (Astrocyte media) stained for H3T22 $\mathrm{cl}$ and DNA using Hoechst stain. Scale bar $=50 \mu \mathrm{m}$. Scatter plot depicting the percentage of H3T22cl-positive cells over total cell count. $(n=4) . * p<0.05, * * p<0.01, * * * p<0.001$, ns: not significant. 


\section{Time-resolved transcriptional changes in Cstb/- neural progenitor cells}

It was previously shown that promoter-associated H3T22 clipping facilitates gene activation in yeast (Santos-Rosa et al., 2009). Based on these observations, we asked whether ectopic initiation of histone $\mathrm{H} 3$ clipping influences gene expression in $\mathrm{Cstb}^{-1}$ NPCs. We performed RNA sequencing (RNAseq) of mRNAs isolated from wt and Cstb ${ }^{-1}$ NPC populations during self-renewal and at days 1, 5 and 12 after induction of differentiation, and determined gene expression changes in the absence of CSTB.

Principal component analysis (PCA) of the transcriptomics data showed that approximately $93 \%$ of the variation between samples (PC1-PC3) originated from the process of differentiation rather than the genotype (Supplementary Appendix, Fig. 5-1). $\mathrm{PCl}$ (77\% of the variation) segregated the RNA samples chronologically, in a well-defined cluster at each timepoint assessed (Fig. 5A). The samples derived from undifferentiated NPCs formed a tight cluster, reflecting a high degree of similarity between their transcriptomes. However, PCA of this timepoint alone consistently separated wt and Cstb1. samples along the $\mathrm{PCl}$ axis (32\% of the variation) (Fig. $5 \mathrm{~A}$ ), indicating that the transcriptional effects of CSTB deficiency manifest already before induction of differentiation, coinciding with premature initiation of histone clipping.

Comparative transcriptome analysis of undifferentiated NPCs revealed a total of 112 differentially expressed genes (DEGs) between genotypes (Fig. 5B and Supplementary Appendix, Table 5-1), 97 of which were upregulated in Cstb ${ }^{-1}$ NPCs. We carried out bioinformatic analyses of these 112 genes using Gene Ontology (GO) enrichment analyses. The functionally related genes are shown in Table 5-2 (Supplementary Appendix). GO analyses of biological processes and molecular functions indicated enrichment of several categories related to cytoplasmic and mitochondrial protein synthesis and control of protein translation, including transcripts such as eukaryotic translation initiation factors Eif2s3y, Eif3a, Eif4a1, Eif4B, and Eif5A, and genes encoding mitochondrial ribosomal proteins, such as M rpl54, M rps10, and M rps15. We also noted enrichment in RNA metabolism -related genes mostly linked to processing and splicing of pre-mRNAs, such as Txnl4a and Hnrnpr. Furthermore, GO cellular components identified 30 mitochondrion-associated genes (Fig. 5C). These included Ndufs3, Uqcrfs1, and Cox6a1, which encode proteins belonging to mitochondrial respiratory complexes I, III and IV, respectively, Ogdh and Dlst, belonging to the oxoglutarate dehydrogenase complex, and Samm50, Tomm20, and Tomm40, which encode proteins of the outer mitochondrial membrane involved in cytosolic protein import and sorting. In addition, GO terms of cellular component indicated transcripts of neuron processes and actin binding involved in regulation of cell shape and migration, such as Pfn1 and Dbnl.

We did not observe other DEGs than Cstb at post-differentiation day 1 and next investigated the 19 and 12 DEGs in Cstb ${ }^{-1-}$ NPCs at days 5 and 12 following induction of differentiation, respectively. At day 5 pD, 14 out of the 19 DEGs were downregulated (Fig. 5B and Supplementary Appendix, Table 5-1). Based on GO functional classifications 
(Supplementary Appendix, Table 5-2), transcripts of electron transport chain and electron transfer activity were enriched. Accordingly, GO cellular component analysis of DEGs in Cstb $\%$ mice (Fig. 5C) showed enrichment in transcripts of oxidative phosphorylation complexes I (Ndufs2), III (Uqcrfs1) and IV (Cox6a1, Cox8a). The 12 DEGs at day 12 pD were all upregulated in $\mathrm{Cstb}^{\%}$ samples (Fig. 5B) and were mostly involved in neuronal maturation and integrity, as judged by enrichment in neuron-related ontologies. Half of the genes were annotated in the cellular component category "neuron projection", and included four transcripts of the distal axon, namely Dpysl3, Snca, Rab3a and Nefl. Our dataset also contained two (Stmn1 and Snca) out of three genes annotated under the biological process "regulation of thrombin-activated receptor signaling pathway", a process involved in neuroinflammation, synaptic transmission and plasticity both in health and in disease (Ben Shimon et al., 2015; Ebrahimi et al., 2017). Notably, mutations in four of the 12 differentially expressed genes have been individually linked to human disorders of the nervous system (Polymeropoulos et al., 1997; Cuesta et al., 2002; Yang et al., 2016; Horga et al., 2017; Alsahli et al., 2018). 
$5 \mathrm{~A}$
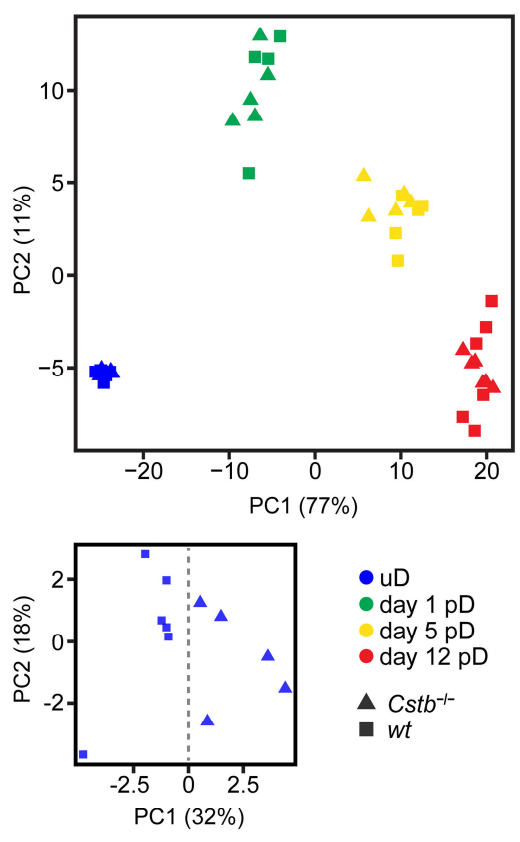

$5 \mathrm{C}$

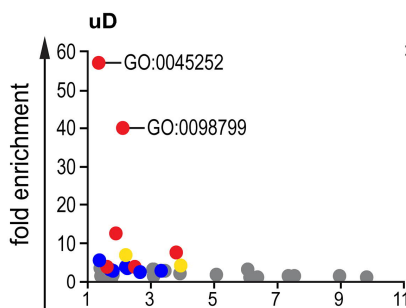

- uD

- day 1 pD

day $5 \mathrm{pD}$

$\Delta$ Cstb $^{-1}$

at
- day 12 pD
$5 B$
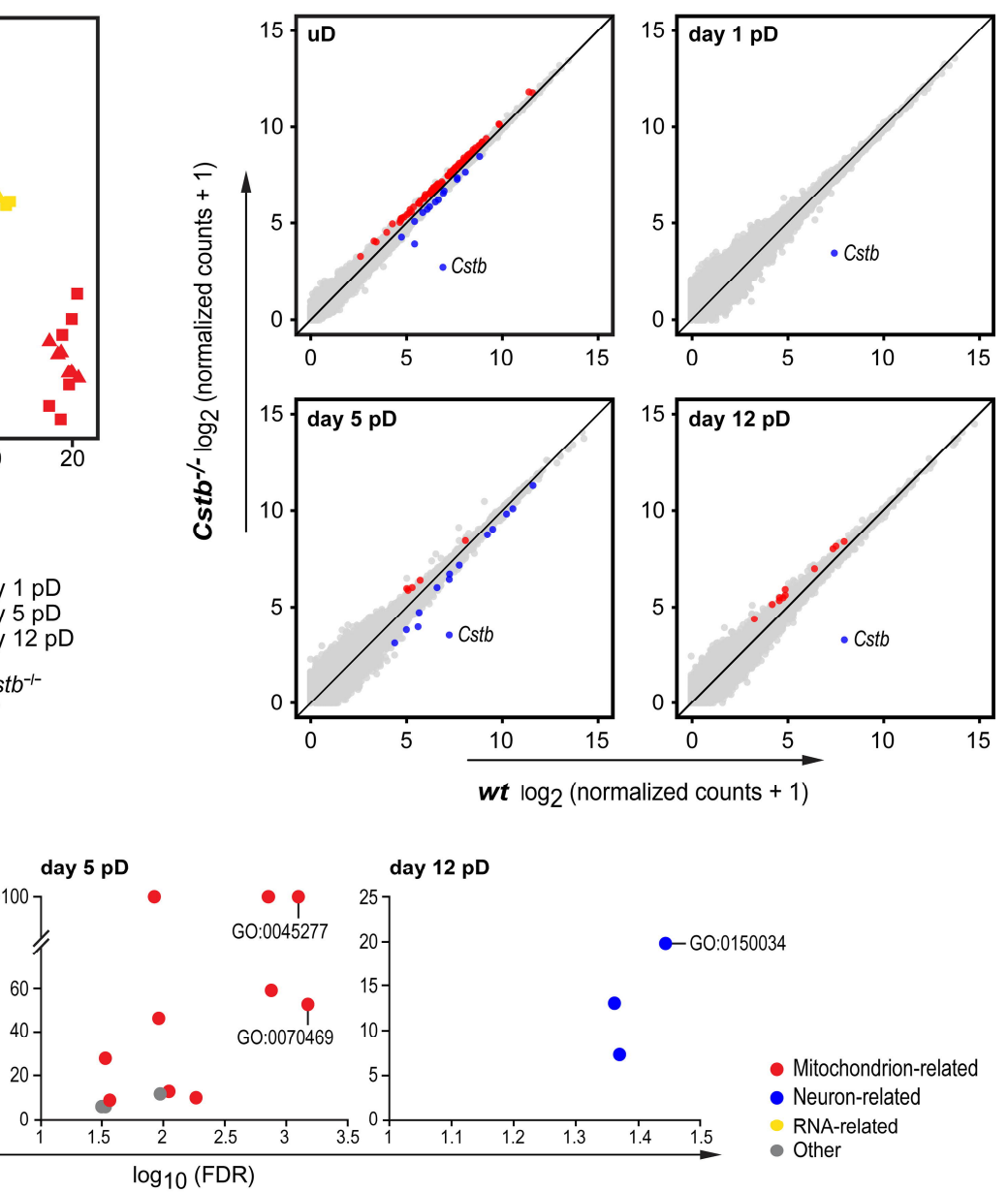

Figure 5: Transcriptional changes during self-renewal and differentiation in Cstb/ NPCs. A: PCA of all 42 mRNA samples analyzed by RNAseq. PCA of undifferentiated samples alone is also displayed. B: Scatter plots depicting all expressed genes per timepoints analyzed. X-axis and Y-axis represent mean gene expression in Cstb $^{-1-}$ and wt mRNAs, respectively. Red and blue dots depict the significantly upregulated and significantly downregulated genes in Cstb ${ }^{-1-}$ samples, respectively. C: Dot charts depicting GO Cellular Component annotations with a statistically significant enrichment among differentially expressed gene datasets in Cstb ${ }^{-/}$at the indicated timepoints. Each category is represented as a dot plotted in relation to its significance level (base 10 logarithm of the false discovery rate $\left(\log _{10} F D R\right), X$-axis) and its fold-enrichment in the dataset (Y-axis). Colored dots represent categories related to mitochondrion, neuron and RNA metabolism as indicated. Examples of top-ranking categories: oxoglutarate dehydrogenase complex (GO:0045252), outer mitochondrial membrane protein complex (G0:0098799), respiratory chain complex IV (GO:0045277), respirasome (GO:0070469), distal axon (GO:0150034). 


\section{Defective mitochondrial respiration in differentiating Cstb/- NPCs}

To characterize the enrichment of functionally related gene sets in the NPC transcriptomes, we ranked all DEGs by expression fold change and carried out gene set enrichment analysis (GSEA). We found that, specifically at days 1 and 5 following induction of differentiation, genes belonging to the GO term "electron transport chain" were significantly enriched at the left pole of the ranking, indicating reduced expression in Cstb ${ }^{-1}$ NPCs (Fig. 6A; q value $=0$ based on 1000 permutations). To further investigate genes in this functional category, we first analyzed, using RT-qPCR in an independently generated set of samples, the expression of electron transport chain genes Ndufs2 and Uqcrfsl and confirmed their downregulation in differentiating Cstb $/-$ NPCs on day $5 \mathrm{pD}$

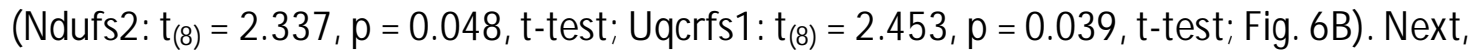
to functionally assess electron transport activity in our cell model, we performed highresolution respirometry of wt and Cstb- ${ }^{-1-}$ NPCs. In undifferentiated cells, mitochondrial respiratory function was not altered between genotypes $\left(\mathrm{Cl} \& \mathrm{Cll}\right.$-linked OXPHOS: $\mathrm{t}_{(3)}=$ 3.131, $\mathrm{p}=0.052$, paired t-test; $\mathrm{CIC}: \mathrm{t}_{(3)}=0.181, \mathrm{p}=0.868$, paired t-test; Supplementary Appendix, Fig. 6-1). Concordant with the GSEA results, differentiating NPCs at day 5 pD presented a significantly lower respiratory capacity in Cstb ${ }^{-/}$than in wt cells (C1\&Clllinked OXPHOS: $\mathrm{t}_{(4)}=5.303, \mathrm{p}=0.006$, paired t-test; $\mathrm{CIC}: \mathrm{t}_{(4)}=4.276, \mathrm{p}=0.013$, paired ttest; Fig. 6C), confirming the onset of mitochondrial dysfunction upon differentiation of CSTB-deficient NPCS.

$6 \mathrm{~A}$

GO: 0022900 "electron transport chain"

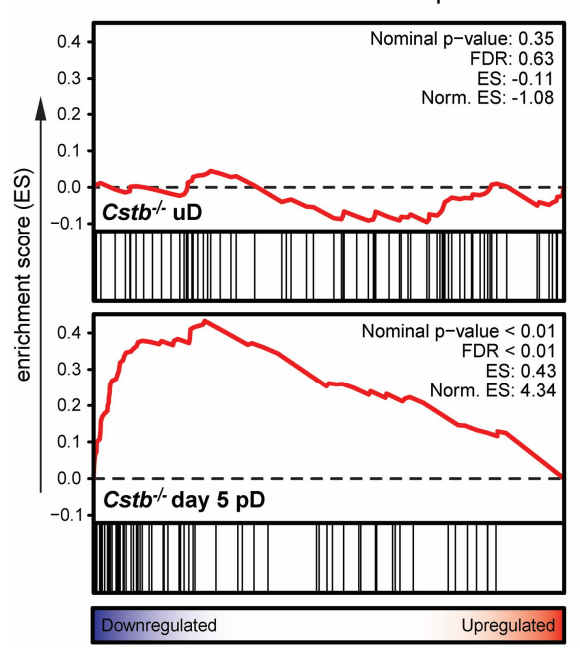

$6 B$

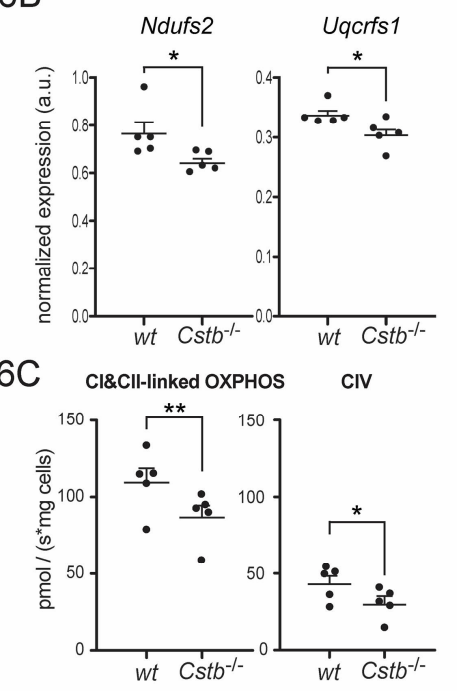

Figure 6: Mitochondrial dysfunction in differentiating Cstb/ $\mathbf{~}^{/ \cdot}$ NPCs. A: GSEA of differentially expressed genes in $\mathrm{Cstb}^{-1}$ NPCs for the GO term electron transport chain. Genes are ranked from left to right from the most downregulated to the most upregulated in $\mathrm{Cstb}^{-/} \mathrm{NPCs}$, respectively (one black line = one gene). $\mathbf{B}:$ RT-qPCR analysis of the electron transport chain genes Ndufs2 and Uqcrfs1 in differentiating wt and Cstb ${ }^{-/}$NPCs at day $5 \mathrm{pD}$. The chart depicts relative expression of target genes as $\triangle \mathrm{Cq}$ normalized to the mRNA levels of housekeeping genes Atp5c1 and Ywhaz $(n=5)$. C: Mitochondrial respiratory capacity measurements using highresolution respirometry in wt and $\mathrm{Cstb}^{-/-} \mathrm{NPCs}$ at day $5 \mathrm{pD}$. The scatter plots depict the rate of oxygen consumption (pmol/s) by maximally coupled respiration (state III) through oxidative phosphorylation complexes I and II (CI\&CII-linked OXPHOS) and individually assessed IV (CIV) normalized to protein input where each measurement represents cells derived from an individual animal $(\mathrm{n}=5) . * p<0.05, * * p<0.01$. 


\section{DISCUSSION}

Transitions between cellular phenotypes require changes to the structure of chromatin (Dixon et al., 2015). Stem cell differentiation, for instance, involves the generation of a more restrictive chromatin state aimed at coping with the functional requirements of a specialized cellular identity (Burney et al., 2013; Zhu et al., 2013). Chromatin regulatory mechanisms are under tight control, for their synchronous action will ultimately determine the gene expression profile of the cell (Chen and Dent, 2014; Petruk et al., 2017). The proteolytic removal of histone tails, particularly of the $\mathrm{N}$-terminal tail of histone $\mathrm{H} 3$, is one of these mechanisms. To date, clipping of the $\mathrm{H} 3$ tail has been observed in eukaryotic organisms from yeast to human (Santos-Rosa et al., 2009; Khalkhali-Ellis et al., 2014; Vossaert et al., 2014), has been implicated in several biological contexts such as embryonic stem cell differentiation, cellular senescence and stress response (Duncan et al., 2008; Duarte et al., 2014; Shen et al., 2017), and has been shown to impact nuclear processes from transcription to chromatin compaction (Santos-Rosa et al., 2009; Nurse et al., 2013; Duarte et al., 2014). Despite this diversity, little is known about the mechanisms upstream of histone tail removal, and its physiological significance in mammalian cells remains largely elusive (Azad et al., 2018; Yi and Kim, 2018). In the present study, we show that lack of the cysteine protease inhibitor CSTB leads to disproportionate cleavage of histone $\mathrm{H} 3$ in cells of the neural lineage. In humans, partial lack of CSTB is the most common underlying cause of progressive myoclonus epilepsy, EPM 1 (Pennacchio et al., 1996), and complete lack of CSTB results in neonatal-onset progressive microcephaly (M ancini et al., 2016; O'Brien et al., 2017) (Fig. 1). By establishing a link between histone clipping and neurologic disease, our findings provide evidence that this epigenetic mechanism serves an irreplaceable function during brain development.

Until now, over a dozen enzymes have been shown to proteolytically process the $\mathrm{N}$ terminal tail of histone $\mathrm{H} 3$ (Yi and Kim, 2018). However, of these only cathepsin L and an as yet unidentified serine protease involved in yeast sporulation were associated with $\mathrm{H} 3$ clipping at threonine 22 in living cells. We identified two seemingly independent modalities of histone $\mathrm{H} 3$ tail clipping in the context of neural stem cell differentiation of cultured NPCS. CSTB deficiency had no perceivable effect on the levels of histone H3 cleaved between amino acids 23 and 27, implying that this modification is not cysteine cathepsin dependent. On the contrary, CSTB deficiency impacted H3T22 proteolysis, with our data suggesting that not only cathepsin $L$, but also cathepsin B is responsible for this event. Considering the degree of complexity found in the mammalian nervous system, it is perhaps not unexpected to find redundancy in the machinery driving neural stem cell differentiation. Indeed, overlapping functions of these two proteases in the nervous system have previously been postulated in that genetically modified mice lacking either cathepsin L or B are viable, whereas double-deficient mice develop severe brain atrophy and die shortly after birth (Nakagawa et al., 1998; Halangk et al., 2000; Felbor et al., 2002). Interestingly, cysteine cathepsin -mediated degradation of histone $\mathrm{H} 3$ was recently shown to impact tissue homeostasis by contributing to chromosome segregation during 
mitosis (Hamalisto et al., 2020). Even if this process and the one reported by us differ significantly in their biological functions, both $\mathrm{H} 3$ truncation events are similarly sensitive to inhibition by CSTB, and are carried out by, at least, cathepsins B and L. The data combined support the view by Dhaenens et al. (2015) that a common group of enzymes has evolved to mediate both homeostatic and epigenetic signaling functions through histone degradation and tail clipping, respectively, in a context-dependent manner.

Antibody-based characterization of differentiating NPCS revealed that the vast majority of $\mathrm{H}_{3} 22 \mathrm{Cl}^{+}$cells were immature committed neurons, which could reflect a longer temporal window for histone clipping in neurons than in glia. Lack of CSTB in our model led to enhanced astrogliogenesis, but did not seem to interfere with the rate of neuron production. In line with the latter observation, RNA sequencing of differentiating wt and $\mathrm{Cstb}^{-1-}$ NPC colonies revealed an overall similar transcriptional profile between genotypes, with only 1 (Cstb), 19 and 12 differentially expressed genes at days 1, 5 and 12 following induction of differentiation. Taken together, these findings indicate that Cstb ${ }^{-1}$ NPCs retain their overall ability to differentiate, and suggest that the sustained cleavage of histone $\mathrm{H} 3$ observed in these cells does not interfere with the differentiation program. Conversely, premature initiation of histone clipping in self-renewing Cstb-1- NPCS was accompanied by subtle transcriptional changes in over a hundred genes. The majority $(86 \%)$ of these genes were upregulated, in accordance with previously published studies linking $\mathrm{H} 3$ tail clipping with transcriptional activation (Santos-Rosa et al., 2009; Kim et al., 2016). These included transcripts involved in mRNA splicing, protein translation and intracellular transport. We also detected a robust enrichment in nuclear encoded mitochondrial genes, representing approximately a quarter of the upregulated DEGs in undifferentiated cells. Interestingly, after induction of differentiation, $\mathrm{Cstb}^{-1}$ cells exhibited a generalized downregulation of electron-transport-chain genes with coinciding significantly reduced mitochondrial respiratory capacity. Mitochondrial metabolism is a cornerstone of neuronal homeostasis (Oyarzabal and Marin-Valencia, 2019; Styr et al., 2019), and has profound implications for both neuronal development and disease (reviewed in Son and Han (2018)). During neural stem cell differentiation, newborn neurons undergo a metabolic transition from aerobic glycolysis to mitochondrial oxidative phosphorylation (Khacho et al., 2016). Considering our finding of histone clipping being heavily enriched among immature neurons, it is tempting to speculate that CSTB deficiency may have an impact on this neurogenesis-associated metabolic switch. Nevertheless, we demonstrate that Cstb ${ }^{-/}$NPCs manifest metabolic defects immediately upon lineage specification. Mitochondrial dysfunction is thus likely to be an important factor contributing to the early pathogenesis of CSTB-deficiency dependent neurodegeneration.

Our data are in line with the recently published findings of neurodevelopmental defects in brain organoids derived from EPM 1 patients (Di Matteo et al., 2020). The authors report premature neuronal differentiation, evidenced by increased levels of DCX- and TUJ1-positive neurons, and smaller organoid sizes accompanied by decreased Ki-67 
expression in neural progenitors lacking CSTB. Accordingly, we found that Cstb ${ }^{-1}$ NPCS at day $12 \mathrm{pD}$ express higher levels of genes involved in neuronal maturation and integrity. However, we did not detect any difference between the genotypes in the proportion of cells expressing DCX, TUJ1 or KI-67, likely reflecting the simplified nature of our cell-based model of neural stem cell differentiation. The divergent results could also signify that CSTB has a more crucial role in human than in mouse brain development. This is further supported by the observation that CSTB null mutations cause rapidly progressing microcephaly in humans, manifesting soon after birth and resulting in severe early functional incapacity (M ancini et al., 2016; O'Brien et al., 2017), whereas the progression of brain atrophy in $\mathrm{Cstb}^{-/-}$mice is more protracted (Pennacchio et al., 1998; Shannon et al., 2002; Tegelberg et al., 2012; Joensuu et al., 2014; Manninen et al., 2014), with deterioration of motor functions appearing later during disease course.

In summary, we show that cysteine cathepsins are responsible for cleavage of the Nterminal tail of histone $\mathrm{H} 3$ at threonine 22 during neural stem cell differentiation. Our data suggest that the cysteine protease inhibitor CSTB plays a dual role in the regulation of this mechanism. On the one hand, it prevents the premature onset of histone clipping in self-renewing progenitors and on the other, it plays a crucial role in the termination of this chromatin-remodeling event in the late stages of differentiation. The latter finding implies that neural cells lacking CSTB are exposed to continuous removal of histone tails following terminal differentiation, a process that would directly interfere with the establishment of maturity-related epigenetic signatures in the $\mathrm{N}$-terminal tail of histone H3. These results constitute the earliest phenotypic changes reported in $\mathrm{Cstb}^{-/}$mice, implying that epigenetic dysregulation is an initial trigger in the pathogenesis of diseases associated with CSTB deficiency.

\section{MATERIALSAND METHODS}

\section{Mouse model}

The Cstb $^{-/}$mouse strain used in this study is 129S2/SvHsd5-Cstb ${ }^{\operatorname{tm} 1 \mathrm{Rm}}$, derived from the Jackson Laboratory strain 129-Cstb ${ }^{\mathrm{tm} 1 \mathrm{Rm} / \mathrm{J}}$ (stock no. 003486; https:// www.jax.org/strain/003486) (Pennacchio et al., 1998). Wild type (wt) mice of the same age and background were used as controls. The research protocols were approved by the Animal Ethics Committee of the State Provincial Office of Southern Finland (decisions ESAVI/ 10765/04.10.07/2015 and ESAVI/ 471/2019).

\section{Primary cell cultures}

The ganglionic eminences of E13.5 mouse embryos were mechanically dissociated and plated at $2 \times 10^{5}$ cells/ $\mathrm{ml}$ in $5 \mathrm{ml}$ maintenance media: Dulbecco's modified Eagle's media (DMEM):F12 (3:1), 2\% B-27, $20 \mathrm{ng} / \mathrm{ml}$ EGF (Millipore), $40 \mathrm{ng} / \mathrm{ml}$ mouse FGF-basic (PeproTech) (Ciccolini and Svendsen, 1998). For passaging, neurospheres were dissociated with TrypLE Express (Gibco) and cultured in maintenance media at $6 \times 10^{4}$ cells $/ \mathrm{ml}$. Experiments were carried out with passage two neurospheres, unless otherwise 
specified. For differentiation, cells were plated onto poly-ornithine-coated surfaces at $3 \mathrm{x}$ $10^{4}$ cells $/ \mathrm{cm}^{2}$ in differentiation media; Standard: Neurobasal media (NB), 2\% B-27, 2\% fetal bovine serum (FBS); Neuron differentiation media, adapted from (Silva et al., 2009; Torrado et al., 2014): NB, 2\% B-27, 1\% FBS, 30 mM glucose, 100 ng/ml BDNF (PeproTech) and $50 \mathrm{ng} / \mathrm{ml}$ bovine serum albumin (BSA); Astrocyte differentiation media, adapted from (Brunet et al., 2004): NB, 2\% B-27, 10\% FBS). For protease inhibitor assays neurospheres were grown with $5 \mu \mathrm{M}$ E-64 (in $\mathrm{H}_{2} \mathrm{O}$ ), $10 \mu \mathrm{M}$ Z-FF-FM K (in DM SO), $10 \mu \mathrm{M}$ CA-074 (in DMSO) (M erck) or correspond ing vehicle for four days prior to harvesting.

\section{Histone extraction and westem blotting}

Bulk histones were isolated from cells or tissue using Histone Extraction Kit (Abcam) and resolved on $4-12 \%$ Bis-Tris Plus Bolt ${ }^{\mathrm{TM}}$ gels at 4-5 ug of protein per lane in MES SDS Running Buffer (Invitrogen). Target-protein signal was detected with Horseradish Peroxidase (HRP) -conjugated secondary antibodies, followed by chemiluminescence reaction and image acquisition using ChemiDoc MP and Image Lab (v6.0; Bio-Rad). For normalization, membranes were gently stripped, re-blocked and re-probed against histone H3 C-terminus.

\section{Enzymatic activity assays}

Substrate-based fluorometric enzymatic activity assays were performed on fresh whole cell lysates of undifferentiated NPCs using Cathepsin L Activity Assay Kit (Abcam) and Cathepsin B Activity Assay Kit (Abcam).

\section{Immunocytochemistry}

Neurospheres were plated onto $12 \mathrm{~mm}$ German glass coverslips (Bellco) and cultured in differentiation media for up to 12 days. Cells were fixed with 4\% PFA for 15 min at RT, followed by permeabilization with $0.1 \%$ Triton X-100 for 10 minutes. Hoechst 33342 (1:2000) was used to counterstain the nuclei.

\section{Antibodies}

Primary antibodies used: rabbit $\alpha$-H3 C-terminus (Abcam, Western blot (WB) 1:15000, RRID: AB_302613), rabbit $\alpha-\mathrm{H} 3 \mathrm{~T} 22 \mathrm{Cl}$ (Cell Signaling Technologies, WB 1:1000, immunocytochemistry (ICC) 1:500, RRID: AB_2797961), rabbit $\alpha$-H3K4me3 (Abcam, WB 1:2000, RRID: AB_306649), rabbit $\alpha-H 3$ K9me3 (Abcam, WB 1:3000, RRID: AB_2797591), rabbit $\alpha-H 3 K 27 m e 2$ (Abcam, WB 1:4000, RRID: AB_448222), mouse $\alpha$-Nestin (Millipore, ICC 1:100, RRID: AB_94911), rabbit $\alpha$-GFAP (Agilent Technologies, ICC 1:200, RRID: $A B \_10013382$ ), rat $\alpha$-GFAP (Thermo Fisher Scientific, ICC 1:500, RRID: AB_2532994), mouse $\alpha$-DCX (Santa Cruz Biotechnology, ICC 1:150, RRID: AB_10610966), mōuse $\alpha$ - $\beta$ IIItubulin (TuJ1) (Millipore, ICC 1:500, RRID: AB_2210524), mouse $\alpha-04$ (Millipore, ICC 1:200, RRID: $A B_{-}$11213138), rat $\alpha-K i-67$ (Thermo Fisher Scientific, ICC 1:200, RRID: $\left.A B \_10853185\right)$. For WB, HRP-conjugated swine $\alpha$-rabbit (Agilent Technologies, RRID: $A B_{-} \_$2617141) was used at 1:8000 to detect $\alpha-H_{3}$ C-terminus and at 1:5000 for all other 
antibody targets. For ICC, fluorescently labeled secondary antibodies (Alexa Fluor 488, 594 and 647; Thermo Fisher Scientific) were used at 1:500.

\section{Expression plasmids and transient transfections}

To produce EGFP-CSTB fusion protein, the coding sequence of CSTB was cloned into an EGFP expression vector (pEGFP-N3, Clontech, GenBank: U57609). The empty EGFP vector was used as a control. C-terminal tagging of CSTB was chosen to prevent interaction with the protease recognition domain found near the $\mathrm{N}$-terminus of the protein. Plasmid delivery through electroporation of passage three neurospheres was performed using M ouse neural stem cell nucleofector kit (Lonza).

\section{RNA sequencing}

\section{Sample collection and library preparation}

A total of 44 neurospheres from three independent cultures were harvested and lysed directly (uD samples) or plated for differentiation in round-bottom 96 -well plates and lysed after 1,5 or 12 days ( $\mathrm{pD}$ samples). To limit the variability arising from clonal heterogeneity (Suslov et al., 2002), we focused the study on middle-sized neurospheres (approx. $200 \mu \mathrm{m}, 400$ cells). Cell lysis in Tris buffer (pH 7) containing 1\% SDS, 10 mM EDTA and $0.2 \mathrm{mg} / \mathrm{ml}$ Proteinase $\mathrm{K}$ was followed by RNA extraction with RNA Clean \& Concentrator kit (Zymo). 48-plex RNAseq libraries were prepared using modified STRT method with unique molecular identifiers (UM Is) (Islam et al., 2011; Islam et al., 2014). In order to remove amplification artefacts at high copy numbers, we used longer UM Is of 8 bp. To increase the coverage, the libraries were sequenced twice with Illumina NextSeq 500 , High Output (75 cycles).

\section{STRT RNAseq data preprocessing}

The raw output base call ( $B C L$ ) files were demultiplexed with Picard (V2.10.10) ExtractllluminaBarcodes and IlluminaBasecallsToSam to generate unaligned BAM files. BAM files were converted to FASTQ files with Picard SamToFastq and aligned to the mouse reference genome mm10, mouse ribosomal DNA unit (GenBank: BK000964), and ERCC spike-ins (SRM 2374) with the GENCODE (vM 19) transcript annotation using HISAT2 (v2.1.0) (Kim et al., 2019). Aligned BAM files were merged with the original unaligned BAM files to generate UM I-annotated BAM files by Picard M ergeBamAlignment. BAM files corresponding to each sample from different lanes and runs were merged using Picard M ergeSamFiles. Potential PCR duplicates were marked with Picard M arkduplicates. The resulting BAM files were processed with featureCounts (v1.6.2) (Liao et al., 2014) to assign the reads to $5^{\prime}$-end of genes. Uniquely mapped reads within the 5'-UTR or $500 \mathrm{bp}$ upstream of protein-coding genes based on the NCBI RefSeq protein-coding genes and the first 50 bp of spike-in sequences were counted. FASTQ files after exclusion of duplicated reads have been deposited in the ArrayExpress database at EM BL-EBI under accession number E-MTAB-8934. The numbers of total and of mapped reads for each sample are summarized in Table 5-3 (Supplementary Appendix). 


\section{RNAseq expression data analysis}

Two samples out of the total 44 samples were excluded due to the extremely low number of mapped reads. After filtering out lowly expressed genes and spike-ins, differential expression analysis between wt and $\mathrm{Cstb}^{-/}$- samples at each timepoint was performed with the 'nbinomWaldTest' method of an R (v3.5.2) package DESeq2 (v1.22.2) (Love et al., 2014). Genes with adjusted p-value less than 0.05 were considered as significantly differentially expressed. Principal component analysis was performed using the 500 genes with the highest variance across all the 42 samples. Gene set enrichment analysis (GSEA) was performed with GSEA (v4.0.3) using GSEAPreranked tool (Subramanian et al., 2005), where genes were preranked based on their $p$-values and fold changes. M ouse gene sets for Gene Ontology were downloaded from http://ge-lab.org/gskb/. GSEA plots were generated using ReplotGSEA.R with some modifications. Gene ontology terms of GO biological processes, GO cellular components and GO molecular functions significantly enriched in our datasets were calculated using Fisher's exact test with BenjaminiHochberg correction using web-based tools WebGestalt (version 01/14/2019) (Liao et al., 2019), Ingenuity Systems Pathway Analysis (IPA, QIAGEN, version 01-14) and the GO Ontology Resource (version 2019-12-09).

\section{Real-Time PCR}

Total RNA was isolated with NucleoSpin RNA Plus kit (Macherey-Nagel) and reversetranscribed with iScript cDNA synthesis kit (BioRad). RT-PCR was performed in CFX96 RealTime System (Bio-Rad) using TaqM an Fast Advanced Master M ix (Applied Biosystems). The following TaqMan probes were used for target amplification: Cstb (M m00432769_m1), Rpl19 (M m02601633_g1), Uqcrfs1 (M m00481849_m1), Ndufs2 (M m00467603_g1). Gene expression data was normalized to that of genes Atp5c1 (M m00662408_m1) and Ywhaz (M m03950126_s1), chosen based on RNA sequencing data for their high and stable expression among timepoints and genotypes. Relative gene expression was calculated using the $2^{-\Delta C t}$ method. All primers were validated and qRT-PCR assays were performed in accordance with M IQE guidelines.

\section{High-resolution respirometry}

Oxygen consumption rates were measured using a substrate-uncoupler-inhibitor protocol on a high-resolution oxygraph (Oroboros Instruments) as previously described (Jackson et al., 2014). Briefly, neurospheres were dissociated with TrypLE express, resuspended in respiration buffer (110 mM D-sucrose, $60 \mathrm{mM}$ lactobionic acid, $20 \mathrm{mM}$ HEPES, $20 \mathrm{mM}$ taurine, $10 \mathrm{mM} \mathrm{KH}_{2} \mathrm{PO}_{4}, 3 \mathrm{mM} \mathrm{M} \mathrm{gCl}, 0.5 \mathrm{mM} \mathrm{EGTA}, 1 \mathrm{~g} / \mathrm{L}$ fatty acid-free BSA, pH7.1) and loaded at $2 \times 10^{6}$ cells per chamber. M easurements were carried out in duplicates. Cells were digitonin-permeabilized, and oxygen consumption rates assessed in the presence of pyruvate-glutamate-malate with specific activities determined with +ADP, and +succinate (CI\&CII-linked maximal coupled respiration, state III), maximal uncoupled respiration by titration of FCCP and individual assessment of complex IV by +Asc/TM PD (CIV). Specific oxygen consumption rates are expressed as pmol/second per million cells. For 
respirometry of day $5 \mathrm{pD}$ samples, cells were washed with PBS, collected by scraping directly in respiration buffer and analyzed as described above with input normalized to amount of protein.

\section{Experimental design and statistical analysis}

A biological replicate $(n)$ was defined as a cell culture or tissue sample derived from an independent pool of mouse embryos ( 3 to 5 individuals from the same litter). In every case, at least three biological replicates were analyzed per condition (timepoint and genotype).

Immunostained cell cultures were imaged with Zeiss Axio Imager M 2 microscope equipped with Axiocam 503 camera (Zeiss). Sample sizes of five or more biological replicates were used. For every biological replicate and condition, 10 random fields were captured with $20 \mathrm{X}$ or $40 \mathrm{X}$ objective. Cell numbers were quantified manually in ZEN software (Zeiss, v2.3). Total number of cells per field was defined by number of nuclei, counted manually or with automated thresholding in ImageJ software.

Data are presented as mean \pm standard error of mean (represented as error bars in figure charts or displayed numerically in tables). Statistical analyses were carried out with GraphPad Prism (v5.0a) or with R Studio software. Comparisons between experimental conditions were made using Student's t-test (unpaired unless otherwise specified) or One-way ANOVA with Bonferroni correction, depending on the experimental setup. For ICC-based characterization of astrogliogenesis, data were analyzed using a linear mixed model followed by a Wald's chi-square test (Chisq). Differences between groups were considered statistically significant when $p<0.05$.

\section{ACKNOWEDGEMENTS}

We thank the Biomedicum Functional Genomics Unit and the Biomedicum Clinical Proteomics unit for skilled technical assistance and advice. This work has been supported by the Folkhälsan Research Foundation, the Sigrid Jusélius Foundation, the Finnish Epilepsy Association, Finska Läkaresällskapet (the M edical Society of Finland), M edicinska Understödsföreningen Liv och Hälsa r.f. ("Life and Health Medical Fund"), and Swedish Research Council. A-E.L. is a HiLIFE Fellow at the University of Helsinki. M .Y. is supported by the Scandinavia-Japan Sasakawa Foundation, the Japan Eye Bank Association, the Astellas Foundation for Research on Metabolic Disorders, and the Japan Society for the Promotion of Science Overseas Research Fellowships. S.K. is supported by Jane and Aatos Erkko Foundation and Swedish Research Council. The computations in this work were performed on resources provided by SNIC through Uppsala Multidisciplinary Center for Advanced Computational Science (UPPM AX) under Project SNIC 2017/7-317.

The authors declare no competing financial interests. 


\section{REFERENCES}

Adams-Cioaba M A, Krupa JC, Xu C, M ort JS, Min J (2011) Structural basis for the recognition and cleavage of histone $\mathrm{H} 3$ by cathepsin L. Nat Commun 2:197.

Alakurtti K, Weber E, Rinne R, Theil G, de Haan GJ, Lindhout D, Salmikangas P, Saukko P, Lahtinen U, Lehesjoki AE (2005) Loss of lysosomal association of cystatin B proteins representing progressive myoclonus epilepsy, EPM 1, mutations. Eur J Hum Genet 13:208-215.

Alsahli S, Al-Twaijri W, AI M utairi F (2018) Confirming the pathogenicity of NECAP1 in early onset epileptic encephalopathy. Epilepsia Open 3:524-527.

Azad GK, Swagatika S, Kumawat M , Kumawat R, Tomar RS (2018) M odifying Chromatin by Histone Tail Clipping. J Mol Biol 430:3051-3067.

Ben Shimon M, Lenz M, Ikenberg B, Becker D, Shavit Stein E, Chapman J, Tanne D, Pick CG, Blatt I, Neufeld M , Vlachos A, M aggio N (2015) Thrombin regulation of synaptic transmission and plasticity: implications for health and disease. Front Cell Neurosci 9:151.

Brunet JF, Grollimund L, Chatton JY, Lengacher S, M agistretti PJ, Villemure JG, Pellerin L (2004) Early acquisition of typical metabolic features upon differentiation of mouse neural stem cells into astrocytes. Glia 46:8-17.

Brännvall K, Hjelm H, Korhonen L, Lahtinen U, Lehesjoki AE, Lindholm D (2003) Cystatin-B is expressed by neural stem cells and by differentiated neurons and astrocytes. Biochemical and biophysical research communications 308:369-374.

Bulynko YA, Hsing LC, Mason RW, Tremethick DJ, Grigoryev SA (2006) Cathepsin L stabilizes the histone modification landscape on the $Y$ chromosome and pericentromeric heterochromatin. Molecular and cellular biology 26:4172-4184.

Burney MJ, Johnston C, Wong KY, Teng SW, Beglopoulos V, Stanton LW, Williams BP, Bithell A, Buckley NJ (2013) An epigenetic signature of developmental potential in neural stem cells and early neurons. Stem Cells 31:1868-1880.

Buzzi A, Chikhladze M, Falcicchia C, Paradiso B, Lanza G, Soukupova M, Marti M, M orari $M$, Franceschetti S, Simonato M (2012) Loss of cortical GABA terminals in Unverricht-Lundborg disease. Neurobiology of disease 47:216-224.

Ceru S, Konjar S, Maher K, Repnik U, Krizaj I, Bencina M, Renko M, Nepveu A, Zerovnik E, Turk B, Kopitar-Jerala N (2010) Stefin B interacts with histones and cathepsin L in the nucleus. The Journal of biological chemistry 285:10078-10086.

Chauhan S, Mandal P, Tomar RS (2016) Biochemical Analysis Reveals the Multifactorial Mechanism of Histone H3 Clipping by Chicken Liver Histone H3 Protease. Biochemistry 55:5464-5482.

Chen T, Dent SY (2014) Chromatin modifiers and remodellers: regulators of cellular differentiation. Nat Rev Genet 15:93-106.

Ciccolini F, Svendsen CN (1998) Fibroblast growth factor 2 (FGF-2) promotes acquisition of epidermal growth factor (EGF) responsiveness in mouse striatal precursor cells: identification of neural precursors responding to both EGF and FGF-2. The Journal 
of neuroscience : the official journal of the Society for Neuroscience 18:78697880.

Cuesta A, Pedrola L, Sevilla T, Garcia-Planells J, Chumillas MJ, M ayordomo F, LeGuern E, Marin I, Vilchez JJ, Palau F (2002) The gene encoding ganglioside-induced differentiation-associated protein 1 is mutated in axonal Charcot-Marie-Tooth type 4A disease. Nature genetics 30:22-25.

Dhaenens M, Glibert P, Meert P, Vossaert L, Deforce D (2015) Histone proteolysis: a proposal for categorization into 'clipping' and 'degradation'. Bioessays 37:70-79.

Di Matteo F, Pipicelli F, Kyrousi C, Tovecci I, Penna E, Crispino M, Chambery A, Russo R, Ayo-Martin AC, Giordano M, Hoffmann A, Ciusani E, Canafoglia L, Gotz M, Di Giaimo R, Cappello S (2020) Cystatin B is essential for proliferation and interneuron migration in individuals with EPM 1 epilepsy. EMBO Mol Med 12:e11419.

Dixon JR, Jung I, Selvaraj S, Shen Y, Antosiewicz-Bourget JE, Lee AY, Ye Z, Kim A, Rajagopal N, Xie W, Diao Y, Liang J, Zhao H, Lobanenkov VV, Ecker JR, Thomson JA, Ren B (2015) Chromatin architecture reorganization during stem cell differentiation. Nature 518:331-336.

Duarte LF, Young AR, Wang Z, Wu HA, Panda T, Kou Y, Kapoor A, Hasson D, Mills NR, Ma'ayan A, Narita M, Bernstein E (2014) Histone H3.3 and its proteolytically processed form drive a cellular senescence programme. Nat Commun 5:5210.

Duncan EM , M uratore-Schroeder TL, Cook RG, Garcia BA, Shabanowitz J, Hunt DF, Allis CD (2008) Cathepsin L proteolytically processes histone H3 during mouse embryonic stem cell differentiation. Cell 135:284-294.

Ebrahimi S, Jaberi N, Avan A, Ryzhikov M, Keramati MR, Parizadeh MR, Hassanian SM (2017) Role of thrombin in the pathogenesis of central nervous system inflammatory diseases. J Cell Physiol 232:482-485.

Felbor U, Kessler B, Mothes W, Goebel HH, Ploegh HL, Bronson RT, Olsen BR (2002) Neuronal loss and brain atrophy in mice lacking cathepsins $B$ and $L$. Proceedings of the National Academy of Sciences of the United States of America 99:78837888.

Gerdes J, Schwab U, Lemke H, Stein H (1983) Production of a mouse monoclonal antibody reactive with a human nuclear antigen associated with cell proliferation. Int J Cancer 31:13-20.

Goulet B, Baruch A, M oon NS, Poirier M, Sansregret LL, Erickson A, Bogyo M, Nepveu A (2004) A cathepsin $L$ isoform that is devoid of a signal peptide localizes to the nucleus in $\mathrm{S}$ phase and processes the CDP/Cux transcription factor. Mol Cell 14:207-219.

Halangk W, Lerch M M, Brandt-Nedelev B, Roth W, Ruthenbuerger M, Reinheckel T, Domschke W, Lippert H, Peters C, Deussing J (2000) Role of cathepsin B in intracellular trypsinogen activation and the onset of acute pancreatitis. J Clin Invest 106:773-781.

Hamalisto S, Stahl JL, Favaro E, Yang Q, Liu B, Christoffersen L, Loos B, Guasch Boldu C, Joyce JA, Reinheckel T, Barisic M, Jaattela M (2020) Spatially and temporally 
defined lysosomal leakage facilitates mitotic chromosome segregation. Nat Commun 11:229.

Horga A, Laura M, Jaunmuktane Z, Jerath NU, Gonzalez M A, Polke JM , Poh R, Blake JC, Liu YT, Wiethoff S, Bettencourt C, Lunn M P, M anji H, Hanna M G, Houlden H, Brandner S, Zuchner S, Shy M, Reilly M M (2017) Genetic and clinical characteristics of NEFLrelated Charcot-Marie-Tooth disease. Journal of neurology, neurosurgery, and psychiatry 88:575-585.

Islam S, Kjallquist U, Moliner A, Zajac P, Fan JB, Lonnerberg P, Linnarsson S (2011) Characterization of the single-cell transcriptional landscape by highly multiplex RNA-seq. Genome research 21:1160-1167.

Islam S, Zeisel A, Joost S, La M anno G, Zajac P, Kasper M , Lonnerberg P, Linnarsson S (2014) Quantitative single-cell RNA-seq with unique molecular identifiers. Nature methods 11:163-166.

Jackson CB, Nuoffer JM , Hahn D, Prokisch H, Haberberger B, Gautschi M, Haberli A, Gallati $S$, Schaller A (2014) Mutations in SDHD lead to autosomal recessive encephalomyopathy and isolated mitochondrial complex II deficiency. Journal of medical genetics 51:170-175.

Joensuu T, Kuronen M, Alakurtti K, Tegelberg S, Hakala P, Aalto A, Huopaniemi L, Aula N, Michellucci R, Eriksson K, Lehesjoki AE (2007) Cystatin B: mutation detection, alternative splicing and expression in progressive myclonus epilepsy of UnverrichtLundborg type (EPM 1) patients. Eur J Hum Genet 15:185-193.

Joensuu T, Tegelberg S, Reinmaa E, Segerstrale M, Hakala P, Pehkonen H, Korpi ER, Tyynela J, Taira T, Hovatta I, Kopra O, Lehesjoki AE (2014) Gene expression alterations in the cerebellum and granule neurons of Cstb(-/-) mouse are associated with early synaptic changes and inflammation. PloS one 9:e89321.

Khacho M, Clark A, Svoboda DS, Azzi J, M acLaurin JG, M eghaizel C, Sesaki H, Lagace DC, Germain M , Harper ME, Park DS, Slack RS (2016) M itochond rial Dynamics Impacts Stem Cell Identity and Fate Decisions by Regulating a Nuclear Transcriptional Program. Cell Stem Cell 19:232-247.

Khalkhali-Ellis Z, Goossens W, M argaryan NV, Hendrix MJ (2014) Cleavage of Histone 3 by Cathepsin D in the involuting mammary gland. PloS one 9:e103230.

Kim D, Paggi JM, Park C, Bennett C, Salzberg SL (2019) Graph-based genome alignment and genotyping with HISAT2 and HISAT-genotype. Nat Biotechnol 37:907-915.

Kim K, Punj V, Kim JM, Lee S, Ulmer TS, Lu W, Rice JC, An W (2016) M MP-9 facilitates selective proteolysis of the histone $\mathrm{H} 3$ tail at genes necessary for proficient osteoclastogenesis. Genes \& development 30:208-219.

Koskenkorva P, Niskanen E, Hypponen J, Kononen M, M ervaala E, So ininen H, Kalviainen $\mathrm{R}$, Vanninen R (2012) Sensorimotor, visual, and auditory cortical atrophy in Unverricht-Lundborg disease mapped with cortical thickness analysis. AJNR Am J Neuroradiol 33:878-883.

Koskenkorva P, Khyuppenen J, Niskanen E, Kononen M, Bendel P, Mervaala E, Lehesjoki $A E$, Kalviainen R, Vanninen R (2009) Motor cortex and thalamic atrophy in 
Unverricht-Lundborg disease: voxel-based morphometric study. Neurology 73:606-611.

Kälviäinen R, Khyuppenen J, Koskenkorva P, Eriksson K, Vanninen R, M ervaala E (2008) Clinical picture of EPM 1-Unverricht-Lundborg disease. Epilepsia 49:549-556.

Lalioti MD, Mirotsou M, Buresi C, Peitsch MC, Rossier C, Ouazzani R, Baldy-M oulinier M, Bottani A, Malafosse A, Antonarakis SE (1997) Identification of mutations in cystatin $B$, the gene responsible for the Unverricht-Lundborg type of progressive myoclonus epilepsy (EPM 1). American journal of human genetics 60:342-351.

Liao Y, Smyth GK, Shi W (2014) featureCounts: an efficient general purpose program for assigning sequence reads to genomic features. Bioinformatics 30:923-930.

Liao Y, Wang J, Jaehnig EJ, Shi Z, Zhang B (2019) WebGestalt 2019: gene set analysis toolkit with revamped UIs and APIs. Nucleic Acids Res 47:W 199-W205.

Love M I, Huber W, Anders S (2014) Moderated estimation of fold change and dispersion for RNA-seq data with DESeq2. Genome biology 15:550.

Mancini GM, Schot R, de Wit MC, de Coo RF, Oostenbrink R, Bindels-de Heus K, Berger LP, Lequin $M H$, de Vries FA, Wilke M, van Slegtenhorst M A (2016) CSTB null mutation associated with microcephaly, early developmental delay, and severe dyskinesia. Neurology 86:877-878.

Manninen O, Laitinen T, Lehtimaki KK, Tegelberg S, Lehesjoki AE, Grohn O, Kopra 0 (2014) Progressive volume loss and white matter degeneration in cstb-deficient mice: a diffusion tensor and longitudinal volumetry MRI study. PloS one 9:e90709.

M anninen O, Koskenkorva P, Lehtimaki KK, Hypponen J, Kononen M, Laitinen T, Kalimo H, Kopra O, Kalviainen R, Grohn O, Lehesjoki AE, Vanninen R (2013) White matter degeneration with Unverricht-Lundborg progressive myoclonus epilepsy: a translational diffusion-tensor imaging study in patients and cystatin B-deficient mice. Radiology 269:232-239.

M elo FR, Wallerman O, Paivandy A, Calounova G, Gustafson AM, Sabari BR, Zabucchi G, Allis CD, Pejler G (2017) Tryptase-catalyzed core histone truncation: A novel epigenetic regulatory mechanism in mast cells. J Allergy Clin Immunol 140:474485.

M orin V, Sanchez-Rubio A, Aze A, Iribarren C, Fayet C, Desdevises Y, Garcia-Huidobro J, Imschenetzky M, Puchi M, Geneviere AM (2012) The protease degrading sperm histones post-fertilization in sea urchin eggs is a nuclear cathepsin $L$ that is further required for embryo development. PloS one 7:e46850.

Nakagawa T, Roth W, Wong P, Nelson A, Farr A, Deussing J, Villadangos JA, Ploegh H, Peters C, Rudensky AY (1998) Cathepsin L: critical role in li degradation and CD4 T cell selection in the thymus. Science 280:450-453.

Nurse NP, Jimenez-Useche I, Smith IT, Yuan C (2013) Clipping of flexible tails of histones $\mathrm{H} 3$ and $\mathrm{H} 4$ affects the structure and dynamics of the nucleosome. Biophys J 104:1081-1088.

O'Brien A, Marshall CR, Blaser S, Ray PN, Yoon G (2017) Severe neurodegeneration, progressive cerebral volume loss and diffuse hypomyelination associated with a homozygous frameshift mutation in CSTB. Eur J Hum Genet 25:775-778. 
Okuneva O, Korber I, Li Z, Tian L, Joensuu T, Kopra O, Lehesjoki AE (2015) Abnormal microglial activation in the Cstb(-/-) mouse, a model for progressive myoclonus epilepsy, EPM 1. Glia 63:400-411.

Okuneva O, Li Z, Korber I, Tegelberg S, Joensuu T, Tian L, Lehesjoki AE (2016) Brain inflammation is accompanied by peripheral inflammation in Cstb (-/-) mice, a model for progressive myoclonus epilepsy. J Neuroinflammation 13:298.

Oyarzabal A, Marin-Valencia I (2019) Synaptic energy metabolism and neuronal excitability, in sickness and health. J Inherit M etab Dis 42:220-236.

Pennacchio LA, Bouley DM, Higgins KM, Scott MP, Noebels JL, Myers RM (1998) Progressive ataxia, myoclonic epilepsy and cerebellar apoptosis in cystatin Bdeficient mice. Nature genetics 20:251-258.

Pennacchio LA, Lehesjoki AE, Stone NE, Willour VL, Virtaneva K, Miao J, D'Amato E, Ramirez L, Faham M, Koskiniemi M, Warrington JA, Norio R, de la Chapelle A, Cox DR, M yers RM (1996) Mutations in the gene encoding cystatin $B$ in progressive myoclonus epilepsy (EPM 1). Science 271:1731-1734.

Petruk S, Cai J, Sussman R, Sun G, Kovermann SK, M ariani SA, Calabretta B, M cM ahon SB, Brock HW, lacovitti L, Mazo A (2017) Delayed Accumulation of H3K27me3 on Nascent DNA Is Essential for Recruitment of Transcription Factors at Early Stages of Stem Cell Differentiation. Mol Cell 66:247-257 e245.

Polymeropoulos MH, Lavedan C, Leroy E, Ide SE, Dehejia A, Dutra A, Pike B, Root H, Rubenstein J, Boyer R, Stenroos ES, Chandrasekharappa S, Athanassiadou A, Papapetropoulos T, Johnson WG, Lazzarini AM, Duvoisin RC, Di lorio G, Golbe LI, Nussbaum RL (1997) Mutation in the alpha-synuclein gene identified in families with Parkinson's disease. Science 276:2045-2047.

Rawlings ND, Barrett AJ (1990) Evolution of proteins of the cystatin superfamily. J Mol Evol 30:60-71.

Riccio M , Di Giaimo R, Pianetti S, Palmieri PP, M elli M, Santi S (2001) Nuclear localization of cystatin $B$, the cathepsin inhibitor implicated in myoclonus epilepsy (EPM 1). Experimental cell research 262:84-94.

Rinne R, Saukko P, Järvinen M, Lehesjoki AE (2002) Reduced cystatin B activity correlates with enhanced cathepsin activity in progressive myoclonus epilepsy. Ann Med 34:380-385.

Santos-Rosa H, Kirmizis A, Nelson C, Bartke T, Saksouk N, Cote J, Kouzarides T (2009) Histone $\mathrm{H} 3$ tail clipping regulates gene expression. Nat Struct M ol Biol 16:17-22.

Sergent-Tanguy S, M ichel DC, Neveu I, Naveilhan P (2006) Long-lasting coexpression of nestin and glial fibrillary acidic protein in primary cultures of astroglial cells with a major participation of nestin(+)/GFAP(-) cells in cell proliferation. Journal of neuroscience research 83:1515-1524.

Shannon P, Pennacchio LA, Houseweart MK, Minassian BA, Myers RM (2002) Neuropathological changes in a mouse model of progressive myoclonus epilepsy: cystatin B deficiency and Unverricht-Lundborg disease. Journal of neuropathology and experimental neurology 61:1085-1091. 
Shen J, Xiang X, Chen L, Wang H, Wu L, Sun Y, Ma L, Gu X, Liu H, Wang L, Yu YN, Shao J, Huang C, Chin YE (2017) JMJD5 cleaves monomethylated histone H3 N-tail under DNA damaging stress. EM BO reports 18:2131-2143.

Silva A, Pereira J, Oliveira CR, Relvas JB, Rego AC (2009) BDNF and extracellular matrix regulate differentiation of mice neurosphere-derived cells into a GABAergic neuronal phenotype. Journal of neuroscience research 87:1986-1996.

Son G, Han J (2018) Roles of mitochondria in neuronal development. BM B Rep 51:549556.

Styr B, Gonen N, Zarhin D, Ruggiero A, Atsmon R, Gazit N, Braun G, Frere S, Vertkin I, Shapira I, Harel M, Heim LR, Katsenelson M, Rechnitz O, Fadila S, Derdikman D, Rubinstein M, Geiger T, Ruppin E, Slutsky I (2019) M itochondrial Regulation of the Hippocampal Firing Rate Set Point and Seizure Susceptibility. Neuron 102:10091024 e1008.

Subramanian A, Tamayo P, M ootha VK, M ukherjee S, Ebert BL, Gillette MA, Paulovich A, Pomeroy SL, Golub TR, Lander ES, M esirov JP (2005) Gene set enrichment analysis: a knowledge-based approach for interpreting genome-wide expression profiles. Proceedings of the National Academy of Sciences of the United States of America 102:15545-15550.

Suslov ON, Kukekov VG, Ignatova TN, Steindler DA (2002) Neural stem cell heterogeneity demonstrated by molecular phenotyping of clonal neurospheres. Proceedings of the National Academy of Sciences of the United States of America 99:1450614511.

Tegelberg S, Kopra O, Joensuu T, Cooper JD, Lehesjoki AE (2012) Early microglial activation precedes neuronal loss in the brain of the Cstb-/- mouse model of progressive myoclonus epilepsy, EPM1. Journal of neuropathology and experimental neurology 71:40-53.

Torrado EF, Gomes C, Santos G, Fernandes A, Brites D, Falcao AS (2014) Directing mouse embryonic neurosphere differentiation toward an enriched neuronal population. Int J Dev Neurosci 37:94-99.

Turk V, Bode W (1991) The cystatins: protein inhibitors of cysteine proteinases. FEBS Lett 285:213-219.

Vossaert L, Meert P, Scheerlinck E, Glibert P, Van Roy N, Heindryckx B, De Sutter P, Dhaenens M, Deforce D (2014) Identification of histone H3 clipping activity in human embryonic stem cells. Stem Cell Res 13:123-134.

Yang Y, Gu LQ, Burnette WB, Li J (2016) N98S mutation in NEFL gene is dominantly inherited with a phenotype of polyneuropathy and cerebellar atrophy. Journal of the neurological sciences 365:46-47.

Yi SI, Kim K (2018) Histone tail cleavage as a novel epigenetic regulatory mechanism for gene expression. BMB Rep 51:211-218.

Zhu J, Adli M , Zou JY, Verstappen G, Coyne M, Zhang X, Durham T, M iri M, Deshpande V, De Jager PL, Bennett DA, Houmard JA, M uoio DM, Onder TT, Camahort R, Cowan CA, Meissner A, Epstein CB, Shoresh N, Bernstein BE (2013) Genome-wide 
chromatin state transitions associated with developmental and environmental cues. Cell 152:642-654.

\section{SUPPLEM ENTARY APPENDIX}

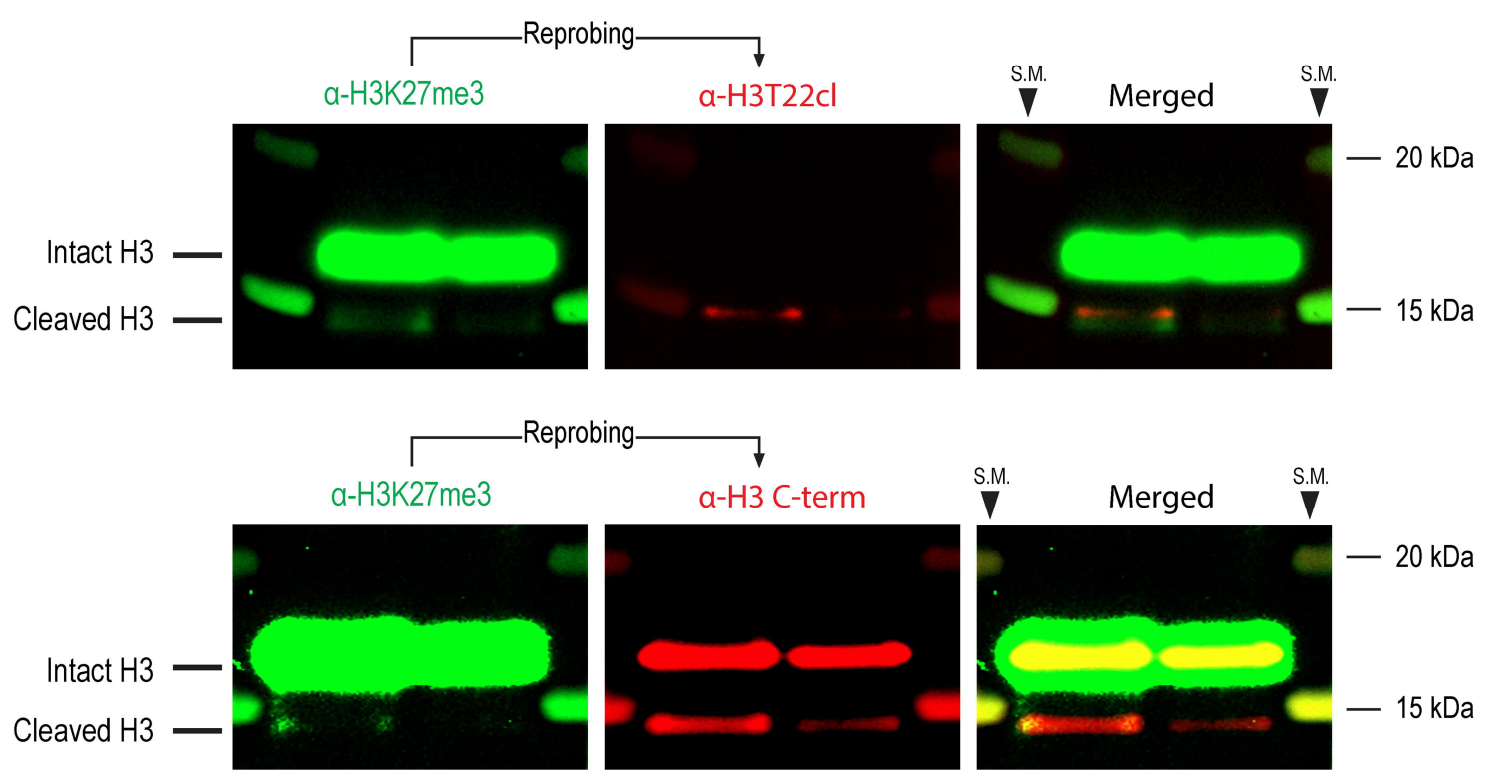

Figure 2-1: Both differentiation-asso ciated H3 cleavage products detected in wt NPCs are proximal to amino acid 27. An antibody against H3K27me3 recognizes both cleavage products of histone $\mathrm{H} 3$ observed upon differentiation of cultured NPCs. Western blot analysis of histone extracts from differentiating wt NPCs at day $5 \mathrm{pD}$. M embranes were probed sequentially with antibodies against H3K27me3 and either H3T22cl (top) or H3 C-terminus (bottom). Lanes from left to right: Protein size marker / $4 \mu \mathrm{g}$ histone / 2 ug histone / Protein size marker. 
A

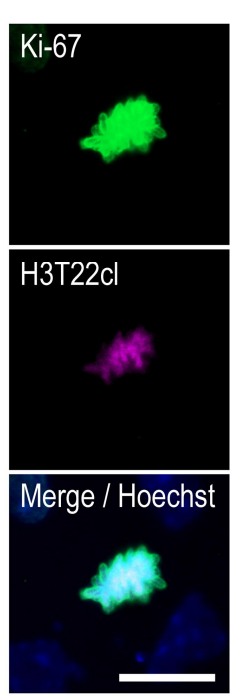

B

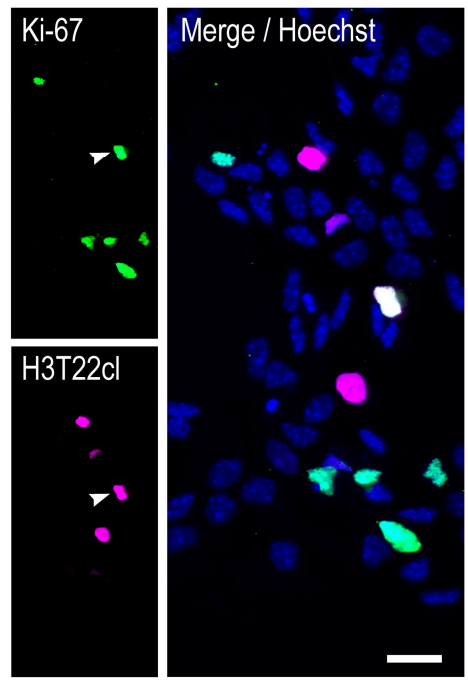

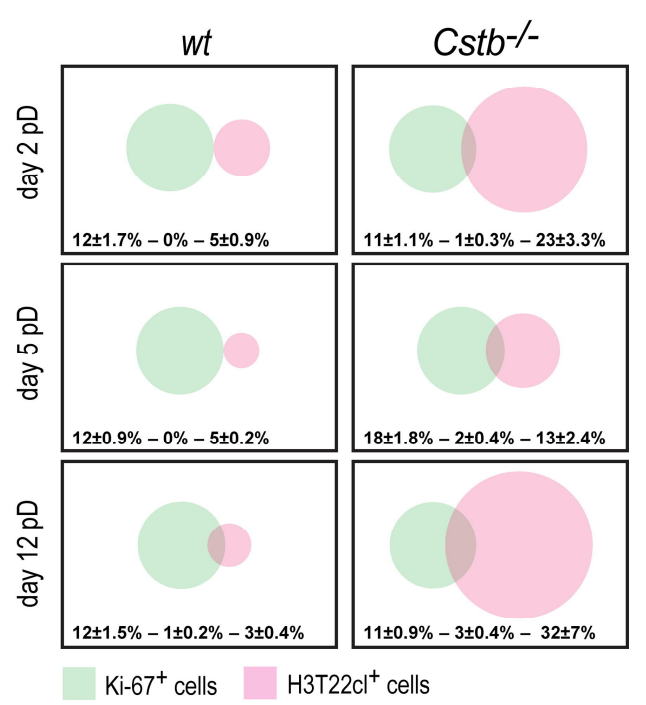

Figure 4-1: H3T22 clipping is most prevalent among non-dividing cells. Immunofluorescence images of differentiating wt NPCs at day 12 pD stained for Ki-67, H3T22Cl and DNA (Hoechst). A: Ki-67 / H3T22 Cl positive cell at the prophase of mitosis. Scale bars $=20 \mu \mathrm{m}$. B: Representative example of the staining with one Ki-67 / H3T22cl positive cell (arrowhead). Venn diagrams depict overlap between Ki-67-positive and H3T22cl-positive cells in relation to the total cell count at the indicated timepoints, both in wt and in Cstb1. cells. Numerical values indicate average proportions \pm standard error of the mean $(n=6)$.
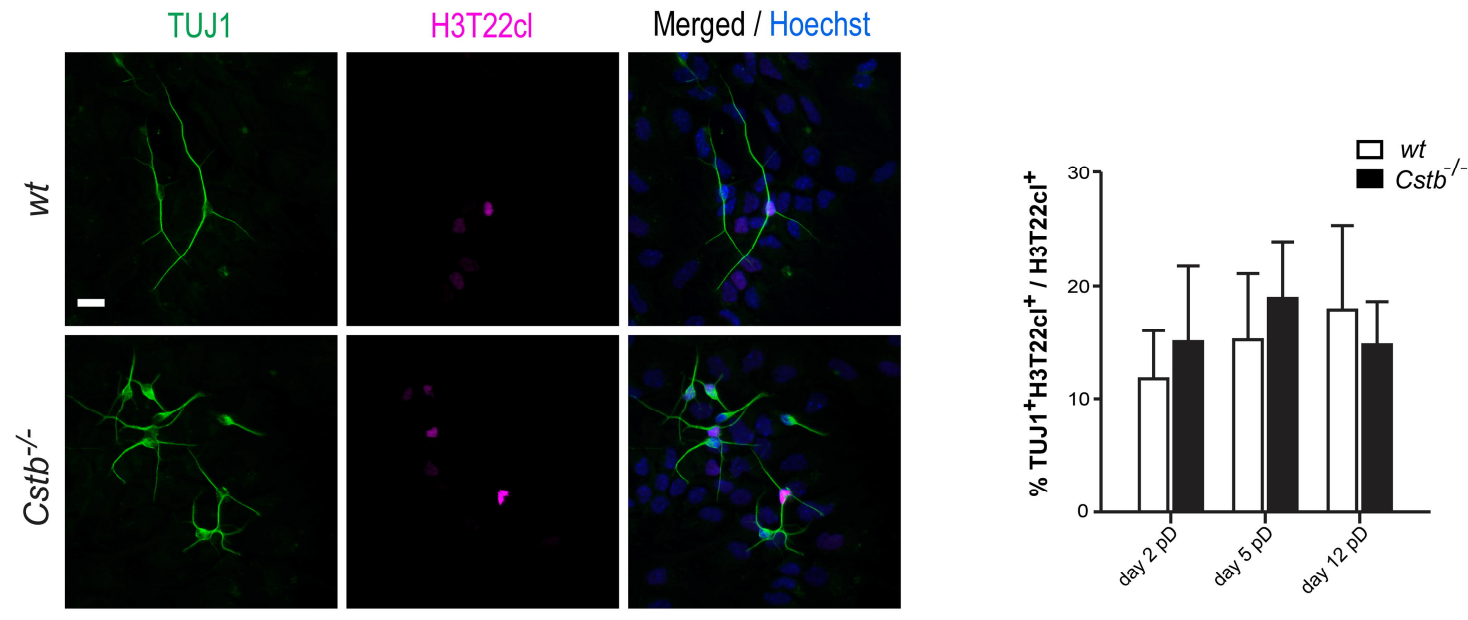

$w t$ day $5 \mathrm{pD}$

Figure 4-2: H3T22 cleavage is enriched in TUJ1-expressing neurons. Representative immunofluorescence images of differentiating wt and Cstb ${ }^{-1-}$ NPCs stained for TUJ 1, H3T22 Cl and DNA (Hoechst). Scale bar $=20$ $\mu \mathrm{m}$. Bar plot depicts the proportion of TUJ1/H3T22 Cl -positive cells over total H3T22Cl-positive cell count ( $n$ $=6$ ). 


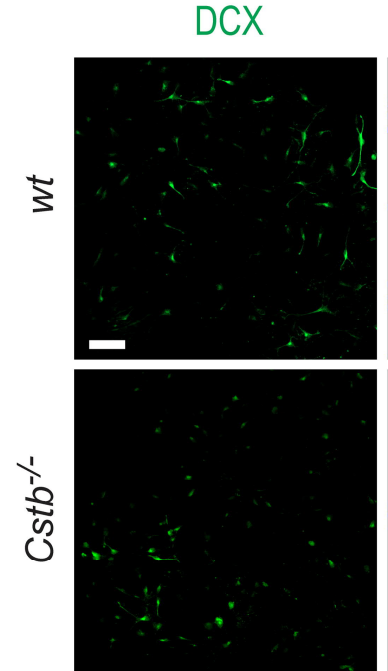

day $2 \mathrm{pD}$
Hoechst
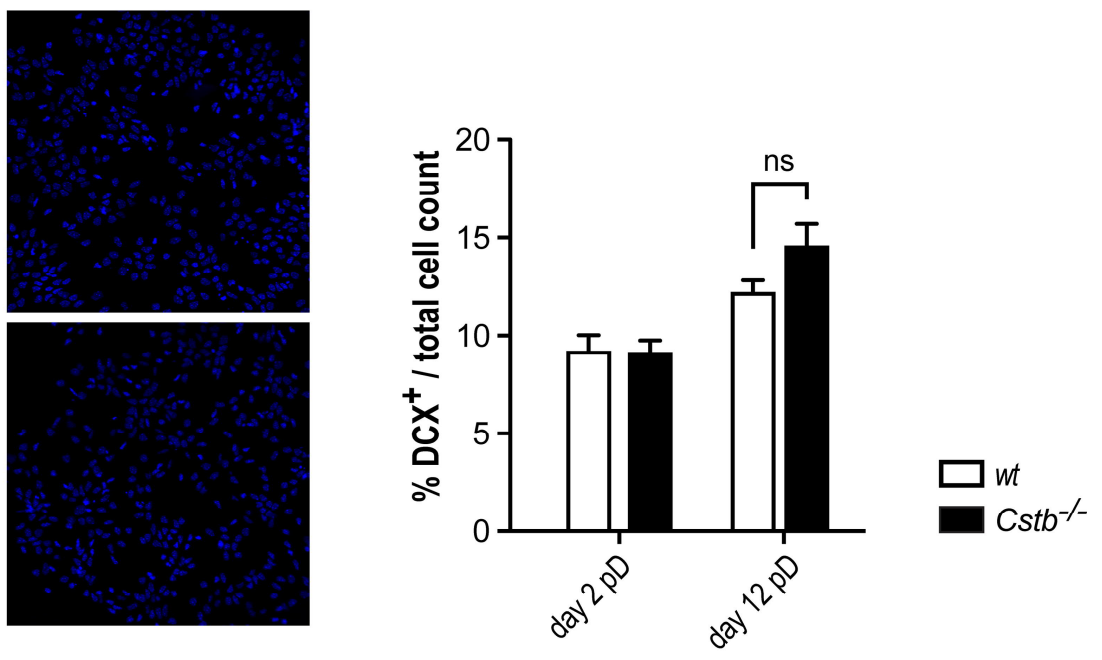

Figure 4-3: Both wt and Cstb ${ }^{-1-}$ NPCs give rise to $D C X^{+}$neurons in similar proportions. Representative immunofluorescence images of differentiating wt and Cstb ${ }^{-1-N P C s}$ stained for doublecortin (DCX) and DNA (Hoechst). Scale bar $=50 \mu \mathrm{m}$. Bar plot depicts the proportion of DCX-positive cells over total cell count $(n=$ 5). ns: not significant.

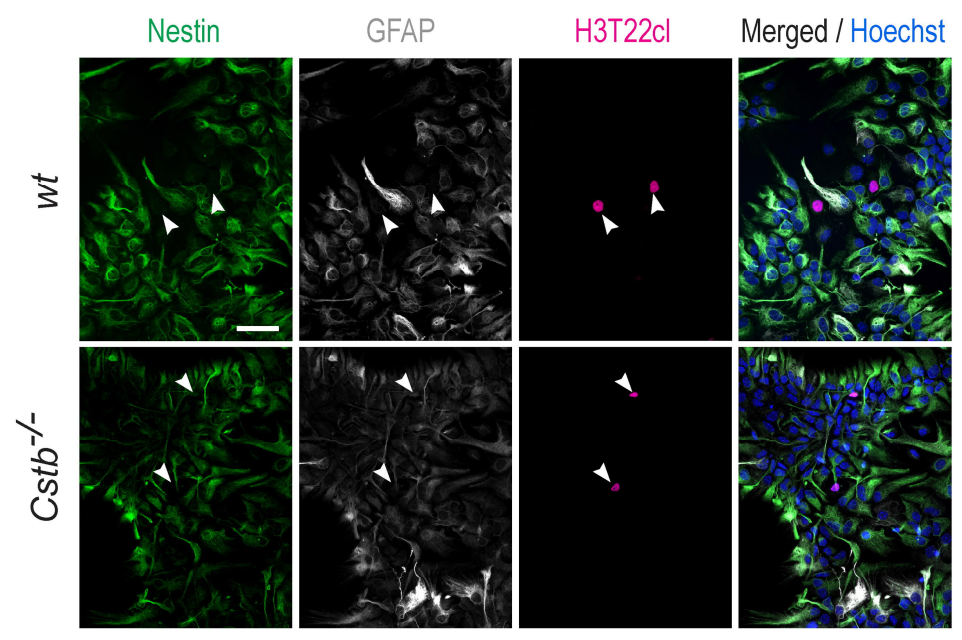

day $5 \mathrm{pD}$

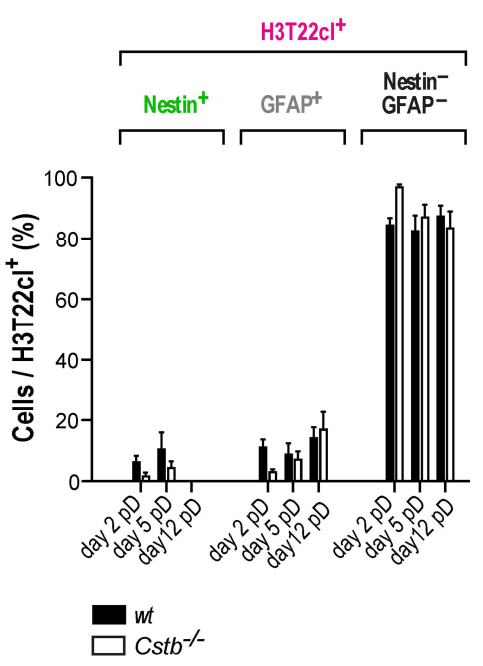

Figure 4-4: The majority of $\mathrm{H} 3 \mathrm{~T} 22 \mathrm{cl}$-positive cells do not express nestin or GFAP. Representative immunofluorescence images of differentiating wt and Cstb ${ }^{-1-}$ NPCS stained for nestin, glial fibrillary acidic protein (GFAP), H3T22 cl and DNA (Hoechst). Arrowheads indicate the locations of H3T22cl-positive cells. Scale bar $=50 \mu \mathrm{m}$. The chart depicts the proportion of nestin-positive, GFAP-positive and nestin/GFAPnegative cells among total H3T22cl-positive cell population ( $n=3-6)$. 


\section{$\mathrm{O} 4$ / H3T22cl / Hoechst}

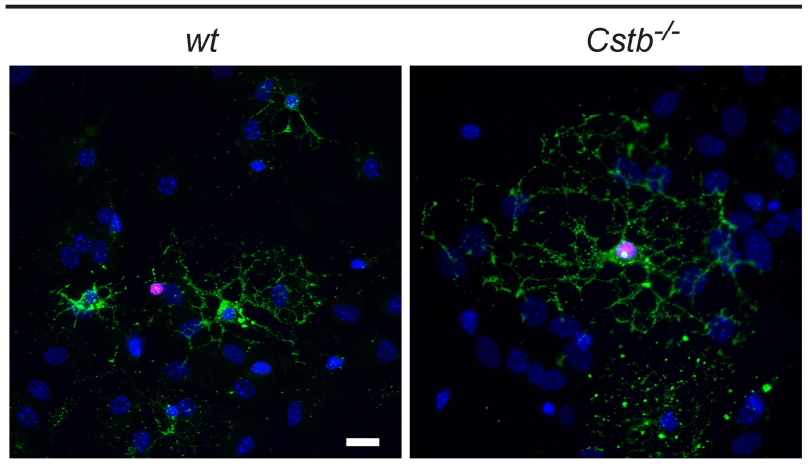

day $12 \mathrm{pD}$

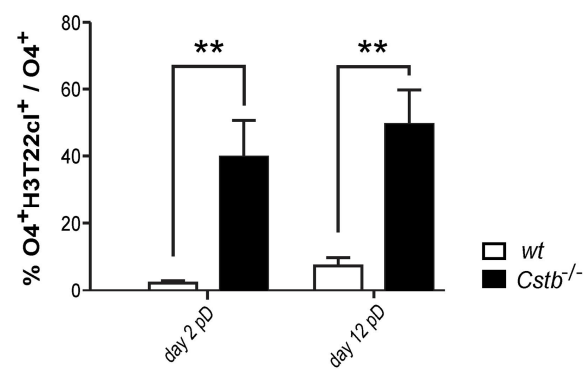

Figure 4-5: Histone H3 tail clipping takes place in cells of the oligodendrocyte lineage. Representative immunofluorescence images of differentiating wt NPCs stained for oligodendrocyte surface antigen 04 and H3T22cl. Scale bar $=20 \mu \mathrm{m}$. The chart depicts the proportion 04 / H3T22 cl -positive cells over 04-positive cell count $(\mathrm{n}=6)$. ** $\mathrm{p}<0.01$.
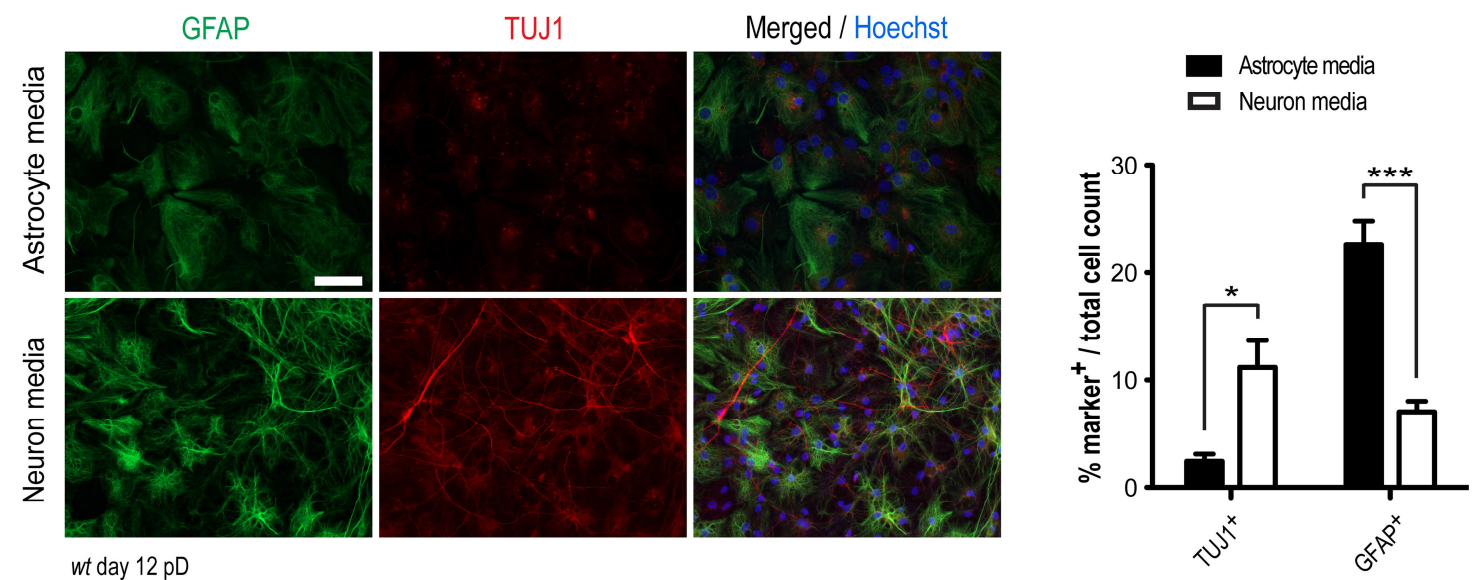

Figure 4-6: Changes in the relative production of neurons and astrocytes upon NPC differentiation in "astrocyte media" and "neuron media". Representative immunofluorescence images of differentiating wt NPCs cultured for 12 days under neurogenesis-promoting conditions (neuron media) and astrogliogenesispromoting conditions (astrocyte media) and stained for GFAP and TUJ 1. Scale bar $=50 \mu \mathrm{m}$. Bar plot depicts the proportion of GFAP-positive and TUJ1-positive cells over total cell count at day $12 \mathrm{pD}(n=4-5)$. * $p<$ 0.05 , *** $p<0.001$. 


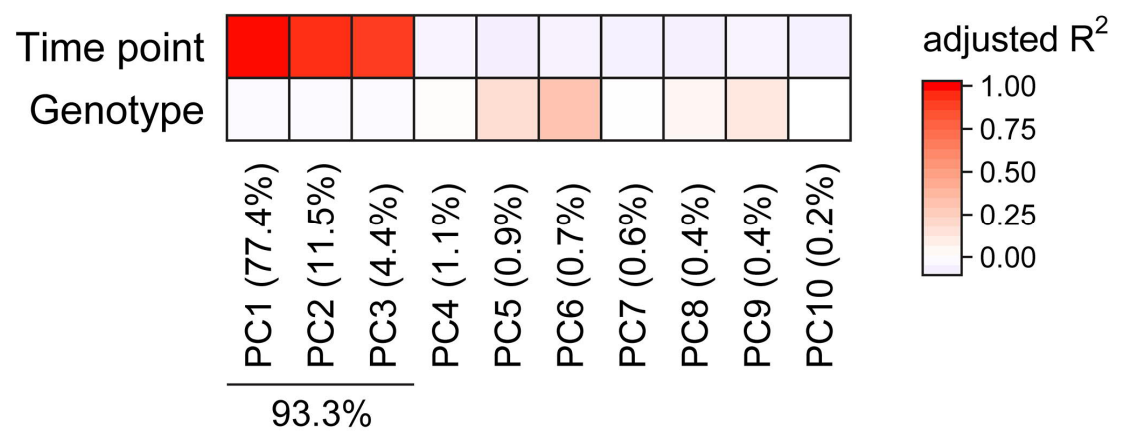

Figure 5-1: Transcriptional divergence among RNA-sequencing samples arises primarily from the process of differentiation. Heat map showing contribution of each of the first ten principal components of the RNAsequencing data to sample variability arising from the timepoints ( $U D$, day $1 \mathrm{pD}$, day $5 \mathrm{pD}$ and day $12 \mathrm{pD}$ ) and genotypes ( $\mathrm{wt}_{\mathrm{t}}$ and $\mathrm{Cstb}^{--}$) analyzed. Colors represent adjusted R-square in linear regression. Proportion of variance explained by each principal component is also shown. Note that PC1 to PC3 account for sample heterogeneity arising exclusively from maturation status, being $93.3 \%$ of the overall sample-to-sample variation.

\section{Cl\&CII-linked OXPHOS}
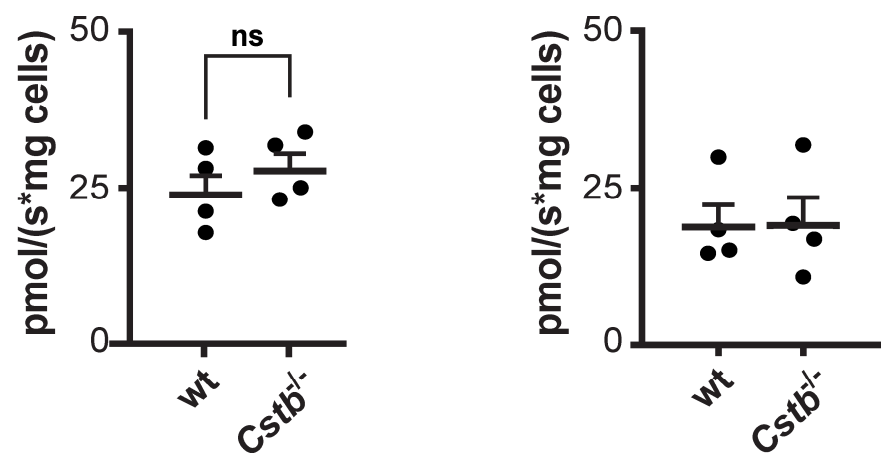

Figure 6-1: Cstb ${ }^{-1-}$ NPCs show statistically normal mitochondrial respiratory capacities before induction of differentiation. Mitochondrial respiratory capacity measurements using high resolution respirometry in undifferentiated wt and Cstb ${ }^{-/}$NPCs. The scatter plots depict the rate of oxygen consumption (pmol/s) by maximally coupled respiration (state III) through oxidative phosphorylation complexes I and II (Cl\&CII-linked OXPHOS) and individually assessed IV (CIV) normalized to input cell number (ttest; $n=4)$. ns: not significant. 
Table 5-1: Differentially expressed genes (DEGs) in undifferentiated and differentiating Cstb ${ }^{-N}$ NPCs at days 1,5 and $12 \mathrm{pD}$.

Table 5-2: Gene Ontology (GO) term enrichment analysis of differentially expressed genes in Cstb ${ }^{-/-}$NPCs for $\mathrm{GO}$ annotation s of biological process, cellular component and molecular function. Analyses were carried out in geneonto logy.org (GO Ontology database version 2019-12-09).

Table 5-3: RNA sequencing summary. 